\title{
Well Log Analysis to Assist the Interpretation of 3-D Seismic Data at Milne Point, North Slope of Alaska
}

Scientific Investigations Report 2005-5048 


\section{Well Log Analysis to Assist the Interpretation of 3-D Seismic Data at Milne Point, North Slope of Alaska}

By Myung W. Lee

Prepared in cooperation with the Bureau of Land Management under interagency agreement LAI 0200015 and the Department of Energy under interagency agreement DE-AT26-97 FT 34342

Scientific Investigations Report 2005-5048 


\section{U.S. Department of the Interior \\ Gale A. Norton, Secretary \\ U.S. Geological Survey \\ Charles G. Groat, Director}

U.S. Geological Survey, Reston, Virginia: 2005

This publication is only available online at URL:

http://pubs.usgs.gov/sir/2005/5048/

For information on other USGS products and ordering information:

World Wide Web: http://www.usgs.gov/pubprod/

Telephone: 1-888-ASK-USGS

For more information on the USGS — the Federal source for science about the Earth, its natural and living resources, natural hazards, and the environment:

World Wide Web: http://www.usgs.gov/

Telephone: 1-888-ASK-USGS

Any use of trade, product, or firm names in this publication is for descriptive purposes only and does not imply endorsement by the U.S. Government.

Although this report is in the public domain, permission must be secured from the individual copyright owners to reproduce any copyrighted materials contained within this report. 


\section{Contents}

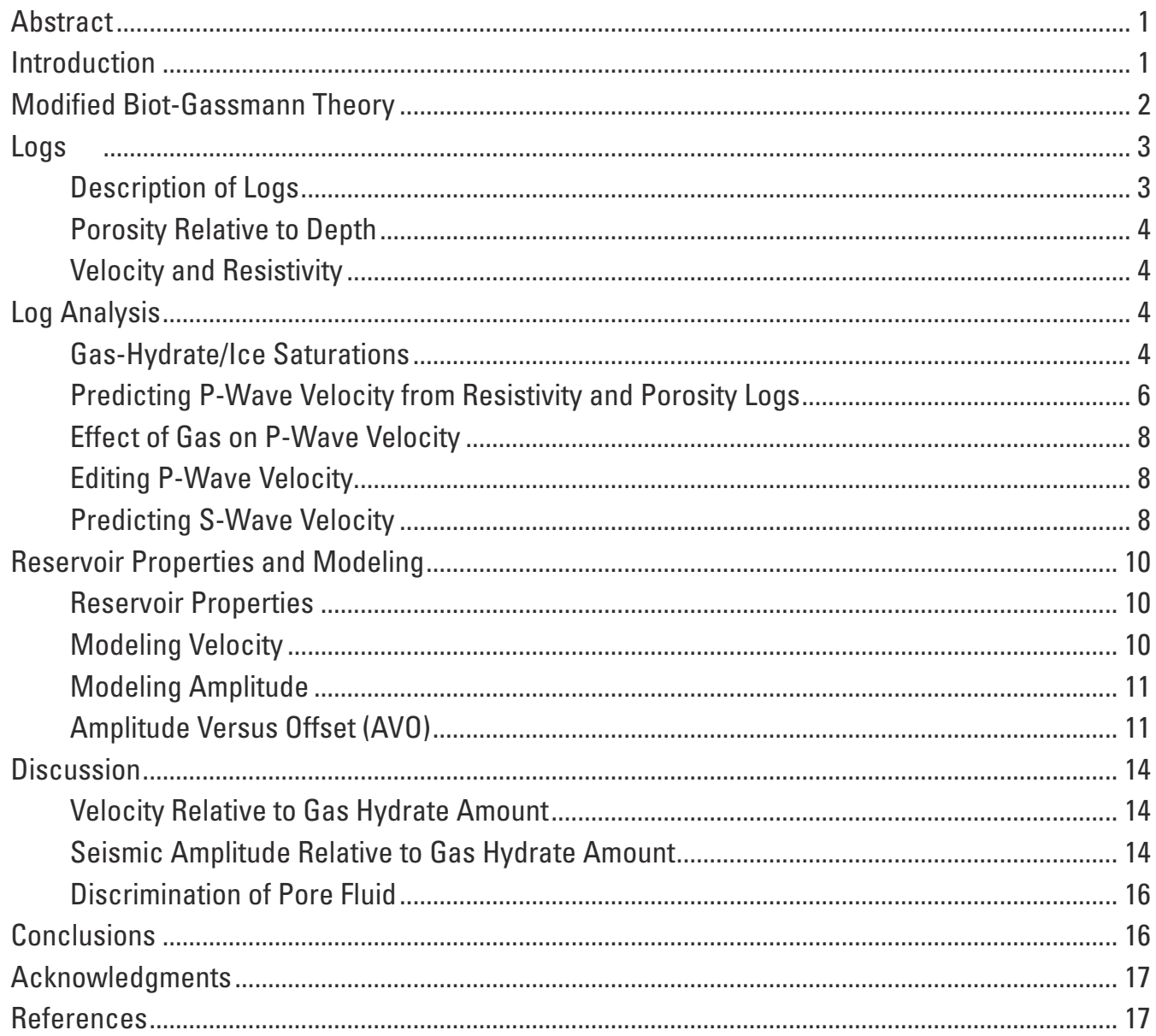

\section{Figures}

1-17. Graphs showing:

1. Relation between measured density porosity and depth (compaction) at

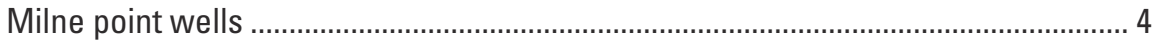

2. The porosity and depth relationship at the CO MPU 2 well....................................... 5

3. The relationship between P-wave velocity and formation resistivity at the CO MPU 1 well

4. Estimated gas-hydrate/ice saturations from the resistivity log and density porosity at the CO MPU 2 well.

5. Predicted P-wave velocities using the gas-hydrate/ice saturations estimated from the resistivity log and porosities plotted against the measured P-wave velocities at the CO MPU 2 well ................................................... 6

6. Porosity and velocity at the AR Fiord 4 well.............................................................. 7 
7. Gas-hydrate and gas saturations estimated from the resistivity log at the Kuparuk State 7-11-12 well and predicted P-wave velocities under the assumption of gas hydrate in the pore space and free gas with the measured P-wave velocities at the Kuparuk State 7-11-12 well

8. An example of velocity editing using the predicted P-wave velocity at the CO MPU 2 well

9. Gas-hydrate and gas saturations estimated from the resistivity log at the CO MPU D-1 well

10. P-wave velocity, density porosity, and clay volume content at the CO MPU D-1 well within the gas-hydrate stability zone

11. Parameters for a typical reservoir of gas-hydrate-bearing sediments and graph showing measured $\mathrm{P}$-wave velocities at depths between 2,500 and 3,000 feet at the CO MPU D-1 well and predicted P-wave velocity for the clean sand and encasing shaly sandstone.

12. Modeled P-wave velocity, density, and reflection coefficient for the reservoir model shown in figure $11 \mathrm{~A}$

13. Modeled reflection amplitude

14. Modeled velocities for gas-hydrate-bearing sediments and partially gas saturated sediments

15. Amplitude versus offset (AVO) relation computed using parameters shown in table 2 .

16. Derived fluid factors from the estimated amplitude versus offset (AVO) intercepts and AVO gradients for modeled AVO data. 15

17. Various relations between gas-hydrate saturation and P-wave velocity 16

\section{Tables}

1. Well name and API numbers for wells used inside the Milne Point area ........................ 3

2. Elastic parameters for modeling 


\title{
Well Log Analysis to Assist the Interpretation of 3-D Seismic Data at Milne Point, North Slope of Alaska
}

\author{
By Myung W. Lee
}

\section{Abstract}

In order to assess the resource potential of gas hydrate deposits in the North Slope of Alaska, 3-D seismic and well data at Milne Point were obtained from BP Exploration (Alaska), Inc. The well-log analysis has three primary purposes: (1) Estimate gas hydrate or gas saturations from the well logs; (2) predict P-wave velocity where there is no measured P-wave velocity in order to generate synthetic seismograms; and (3) edit P-wave velocities where degraded borehole conditions, such as washouts, affected the P-wave measurement significantly. Edited/predicted P-wave velocities were needed to map the gas-hydrate-bearing horizons in the complexly faulted upper part of 3-D seismic volume. The estimated gas-hydrate/gas saturations from the well logs were used to relate to seismic attributes in order to map regional distribution of gas hydrate inside the 3-D seismic grid.

The P-wave velocities were predicted using the modified Biot-Gassmann theory, herein referred to as BGTL, with gashydrate saturations estimated from the resistivity logs, porosity, and clay volume content. The effect of gas on velocities was modeled using the classical Biot-Gassman theory (BGT) with parameters estimated from BGTL.

\section{Introduction}

Great emphasis is being placed on the exploration for and production of cleaner burning natural gas resources. New, unconventional sources of natural gas are being evaluated and produced, but the largest potential source of natural gas is in gas-hydrate-bearing sediments (Kvenvolden, 1993). In order to assist the U.S. Geological Survey assessment of the resource potential of gas hydrate, a 1996 3-D seismic survey shot for BP Exploration (Alaska), Inc., by Northern Geophysical Company, which included part of the Milne Point oil field of the North Slope of Alaska, was released to the USGS along with pertinent well logs.
The subsurface geology at the Milne Point area consists of an upper Paleozoic and Mesozoic, south-facing, passivecontinental-margin sequence and an upper Mesozoic and Cenozoic, north-facing, foreland basin sequence (Collett, 1993). The foreland basin sequence is composed primarily of Cretaceous and Tertiary clastic rocks, where all of the gashydrate-bearing sediments are present and are highly faulted. The Barrow Arch, a structural high located southwest of the 3-D seismic survey area, produces a northeast dip in the strata within the 3-D survey area, influencing the migration of free gas and the presence of gas-hydrate-bearing sediments.

The average surface temperature in this area ranges from $-10^{\circ} \mathrm{C}$ to $-12^{\circ} \mathrm{C}$; the thermal gradient within the ice-bearing permafrost ranges from $1.55^{\circ} \mathrm{C}$ to $4.21^{\circ} \mathrm{C} / 100$ meters, and the thermal gradient below the base of the ice-bearing permafrost varies between $2.69^{\circ} \mathrm{C}$ to $4.36^{\circ} \mathrm{C} / 100$ meters. The gas-hydrate stability zone (GHSZ) depends on temperature and pressure as well as the type of gas. The depth to the top of GHSZ is about 210 meters, and the depth to the bottom of GHSZ is highly variable, ranging from 360 meters at the South Barrow Test Well 8 to 1,288 meters at the Hurl 5-10-113 well (Collett and others, 1988). Because of the shallow depths to the top of the GHZS, permafrost and gas-hydrate-bearing sediments are probably commingled in the upper part of the section.

Gas hydrate and ice are both electrical insulators, and the resistivity response to ice is the same as that of the gas hydrate. Both ice and gas hydrate in the pore space increase elastic velocities, and the increase of elastic velocities depends on the amount of ice or gas hydrate. Therefore, it is difficult to differentiate ice from gas hydrate on the basis of the log responses.

In the Milne Point 3-D area, the gas-hydrate-bearing sediments are highly compartmented due to complex faulting (Inks and others, 2004). Due to this complexity, synthetic seismogram ties to the 3-D seismic data are extremely important. Unfortunately, the velocity logs in the upper part of the section are either missing or of inadequate quality owing to borehole rugosity. To tie the synthetic seismograms to the 3-D seismic data, the velocity logs are either predicted using the resistivity or porosity logs, and poor-quality velocity logs are edited 
using the predicted values of velocities. In order to map the gas-hydrate distribution and saturation, amplitude and velocity responses of typical gas-hydrate-bearing sediments are then modeled using the edited logs.

\section{Modified Biot-Gassmann Theory}

Lee (2003) derived the following shear modulus based on the assumption that $V_{s}=V_{p} G \alpha(1-\phi)^{n}$, where $V_{p}$ is the P-wave velocity, $V_{s}$ is the S-wave velocity, $\alpha$ is the $V_{s} / V_{p}$ of the matrix material, and $\phi$ is porosity. $G$ and $n$ are parameters depending on differential pressure, consolidation, and clay content. The shear modulus is given by

$$
\mu=\frac{\mu_{m a} k_{m a}(1-\beta) G^{2}(1-\phi)^{2 n}+\mu_{m a} \beta^{2} M G^{2}(1-\phi)^{2 n}}{k_{m a}+4 \mu_{m a}\left[1-G^{2}(1-\phi)^{2 n}\right] / 3}
$$

where

$$
\frac{1}{M}=\frac{(\beta-\phi)}{k_{m a}}+\frac{\phi}{k_{f l}}, \text { and }
$$

$k_{m a}, \mu_{m a}, k_{f l}, \phi, \beta$ are the bulk modulus of matrix, the shear modulus of the matrix, the bulk modulus of the fluid, porosity, and the Biot coefficient, respectively.

For bulk modulus of sediments, the Biot-Gassmann theory gives

$$
k=k_{m a}(1-\beta)+\beta^{2} M
$$

Elastic velocities of water-saturated sediments can be computed from the elastic moduli by the following formulas:

$$
V_{p}=\sqrt{\frac{k+4 \mu / 3}{\rho}} \quad \text { and } \quad V_{s}=\sqrt{\frac{\mu}{\rho}}
$$

where

$\rho$ is density of the formation given by $\rho=(1-\phi) \rho_{m a}+\phi \rho_{f l}$

$\rho_{m a}$ and $\rho_{f l}$ are the matrix density and pore fluid density, respectively.

If it is assumed that the velocity ratio, $V_{p} / V_{s}$, is constant irrespective of porosity, which is approximately true for partially gas saturated sediments (Pickett, 1963), the shear modulus of sediments in dry rock can be derived by the following formula (Krief and others, 1990):

$$
\mu=\mu_{m a}(1-\beta)
$$

Conventionally, it is assumed that fluid in the pore space does not change the shear modulus of sediments. In other words, the shear modulus of dry rock is the same as that of water-saturated sediments. Under this assumption, therefore, equation 4 can be used for water-saturated sediments also. On the other hand, equation 1 implies that the shear modulus of water-saturated sediments, derived from the velocity ratio, depends on the fluid in the pore through a constant $M$, defined in equation 1. Even though equation 4 is not part of the Biot-Gassmann theory, in order to differentiate two different approaches of shear modulus, it is conveniently called classical Biot-Gassmann theory (BGT) in the case that equation 4 is used for the shear modulus, and modified Biot-Gassmann theory by Lee (BGTL) in the case that equation 1 is used for the shear modulus (Lee, 2002).

For soft rocks or unconsolidated sediments, the following Biot coefficient is used (Lee, 2002):

$$
\beta=\frac{-68.7421}{1+e^{(\phi+0.40635) / 0.09425}}+0.98469
$$

For hard or consolidated formations, the equation by Krief and others (1990) is used:

$$
\beta=1-(1-\phi)^{3.8}
$$

The exponent $n$ is given by

$$
n=\left[10^{\left(0.426-0.235 \log _{10} p\right)}\right] / m
$$

and $G$ is given by

$$
G=0.9552+0.0448 e^{-C_{v} / 0.06714}-0.18 S^{2}
$$

where

$$
p \text { is differential pressure in MPa, }
$$

$m$ is a constant related to the degree of consolidation,

$C_{v}$ is the decimal clay volume content of the matrix, and

$S$ is the decimal gas-hydrate saturation in the pore space.

For a detailed discussion of parameters $n$ and $G$, consult Lee (2003).

The effect of gas hydrate on elastic velocities is modeled such that gas hydrate acts as part of the frame or the skeleton. The elastic moduli of the composite matrix are computed by Hill's average equation (Hill, 1952).

The matrix of gas-hydrate-bearing sediments is assumed to consist of sand, clay, and gas hydrate. Using the water-filled porosity, $\phi_{f}=(1-S) \phi$, defined in Lee and Collett (2001),

$C_{v}$ as the volume clay content of the matrix, and $S$ as the gas hydrate saturation, the elastic moduli of a composite matrix can be written: 


$$
\begin{gathered}
k_{m a}=\frac{1}{2}\left[\sum_{i=1}^{3} f_{i} k_{m a}^{i}+\left(\sum_{i=1}^{3} f_{i} / k_{m a}^{i}\right)^{-1}\right] \\
\mu_{m a}=\frac{1}{2}\left[\sum_{i=1}^{3} f_{i} \mu_{m a}^{i}+\left(\sum_{i=1}^{3} f_{i} / \mu_{m a}^{i}\right)^{-1}\right] \\
\rho_{m a}=\sum_{i=1}^{3} f_{i} \rho_{m a}^{i}
\end{gathered}
$$

where

$$
\begin{aligned}
& f_{1}=(1-\phi)\left(1-C_{v}\right) /\left(1-\phi_{f}\right) \\
& f_{2}=(1-\phi) C_{v} /\left(1-\phi_{f}\right) \\
& f_{3}=S \phi /\left(1-\phi_{f}\right)
\end{aligned}
$$

where

$f_{1}, f_{2}$, and $f_{3}$ are the volume fractions of sand, clay, and gas hydrate in the matrix, respectively.

In this paper, density porosity or porosity $(\phi)$ is the space occupied by gas hydrate and (or) water, and the water-filled porosity $\left(\phi_{f}\right)$ is the space occupied only by water.

The effect of free gas on elastic velocities in the framework of BGTL is described in Lee (2004). As mentioned in Lee (2002), BGT instead of BGTL should be used for the partially gas saturated sediments. However, the Biot coefficient that is appropriate for unconsolidated sediments at a given differential pressure is not readily available. Therefore, Lee (2004) used the BGTL to derive the appropriate Biot coefficient for partially gas saturated sediment, which is given by

$$
\beta_{b g t}=1-\frac{\mu_{b g t l}}{\mu_{m a}}
$$

where

$\beta_{b g t}$ is the appropriate Biot coefficient for the BGT in calculating velocities for partially gas saturated sediments; that is, substituting $\beta_{b g t}$ into $\beta$ in equations 2 and 4 , where $\mu_{b g t l}$ is the shear modulus of water-saturated sediments at a given differential pressure calculated using equation 1.

\section{Logs}

\section{Descriptions of Logs}

The purposes of this study are to estimate gas-hydrate/ice and free gas saturations, to predict $\mathrm{P}$-wave velocities for the interval where there are no velocity logs, and to edit velocity logs where velocity logs contain large errors due to hole condition. The primary logs used in this study are gamma, bulk density, electrical resistivity, and P-wave sonic logs. Most of density and P-wave velocity logs start at depths deeper than the expected permafrost/gas-hydrate stability zone in this region. Wells used in this investigation inside the Milne Point area are shown in table 1.

Density porosities were derived from the bulk density $\operatorname{logs}$ with the matrix density of $2.65 \mathrm{~g} / \mathrm{cm}^{3}$ (grams per cubic centimeter) and water density of $1.0 \mathrm{~g} / \mathrm{cm}^{3}$, assuming a twocomponent system (water and matrix). The porosity correction due to the presence of gas-hydrate/ice is accomplished simultaneously with the estimation of gas hydrate (Lee and Collett, 1999), and the correction for free gas is shown later in this report.

Clay volume content $\left(C_{v}\right)$ is calculated from the shifted gamma log by using the following formula pertinent to Tertiary clastics:

$$
C_{v}=0.083\left(2^{3.7 I_{n}}-1\right)
$$

where

$$
I_{n}=\frac{G-G_{c n}}{G_{s h}-G_{c n}} \quad \text { and }
$$

$G, G_{c n}$, and $G_{s h}$ are measured gamma log, gamma log response in a zone considered clean, and log response in a shale bed (Western Atlas International Inc., 1995), respectively.

In this analysis, $G_{c n}$ is about 20-25 in API units and $G_{s h}$ is about $120-180$ in API units.

Table 1. Well name and API numbers for wells used inside the Milne Point area.

[API, American Petroleum Institute]

\begin{tabular}{clc}
\hline Well name & Operator & API number \\
\hline CO MPU 1 & Conoco Inc. & 50029203760000 \\
CO MPU 2 & Conoco Inc. & 50029204900000 \\
CO MPU B-2 & Conoco Inc. & 50029206620000 \\
CO MPU C-1 & Conoco Inc. & 50029206630000 \\
CO MPU D-1 & Conoco Inc. & 50029206640000 \\
AR Fiord 4 & Arco Alaska Inc. & 50103202890000 \\
AR Fiord 5 & Arco Alaska Inc. & 50103202920000 \\
MO Kuparuk St 7-11-12 & Mobil Oil Corp. & 50029200620000 \\
\hline
\end{tabular}




\section{Porosity Relative to Depth}

In order to estimate gas-hydrate/ice saturations either from resistivity or velocity logs, porosity is required. Porosity usually decreases with depth depending on grain geometry, packing, compaction, and cementation. Figure 1 shows the measured porosity/depth relationship at Milne Point wells with two empirical curves; large open circles show the empirical relationship of depth relative to porosity for sandstone, and large diamond symbols show this relationship for shale. The dashed line in figure 1 is a least-squares-fit (LSF) curve to the measured porosity at the CO MPU D-1 well, which is given by $\phi=0.532 e^{-d / 6442}$, where $d$ is depth in feet; the LSF appears to fit the adjacent wells in this area adequately. The majority of porosity data shown in figure 1 lies between clean sandstone and shale curves. The rest of the well-log data in this study area indicates that it is appropriate to use the LSF curve shown in figure 1 with a bias to fit the local porosity/velocity trend. An example at the CO MPU 2 well is shown in figure 2.

The upper part of the porosity log, where the density porosities are not available, is supplemented by the porosity from the compaction curve with a bias -0.02 . The bias of -0.02 suggests that the sediments at the CO MPU 2 well are slightly more compacted than sediments at the CO MPU D-1 well.

\section{Velocity and Resistivity}

Both velocity and resistivity strongly depend on porosity. Therefore, in general, the resistivity and velocity trends are similar to each other. However, in this study area, this relationship is not simple. Figure 3 shows an example of the relationship between resistivity and $\mathrm{P}$-wave velocity at $\mathrm{CO}$ MPU 1 well. Three branches have been interpreted. The first branch is defined for depth interval less than about 2,500 ft, where the P-wave velocity increases as resistivity increases mainly from the accumulation of gas-hydrate/ice in the pore space. The second branch is defined for depths between 2,500 $\mathrm{ft}$ and 5,600 ft, where the P-wave velocity decreases as the resistivity increases, mainly because the resistivity of connate water decreases as depth increases in this interval. The second branch is observed at almost all well logs measured below gashydrate-bearing sediments, where the excluded salts during the formation of gas hydrate could have migrated downward due to gravity. The third branch is for depths greater than $5,600 \mathrm{ft}$, where the P-wave velocity increases as the resistivity increases, mainly because of the compaction and consolidation. The rate of velocity increase with respect to resistivity for Branch 3 is higher than the rate that for Branch 1, which implies that the effect of consolidation on velocity is higher than the effect of gas-hydrate/ice saturation in the pore. For a given velocity, the resistivity for Branch 1 is more than one order of magnitude higher than resistivity that for Branch 3, reflecting the effect of resistivity of connate water and shale.

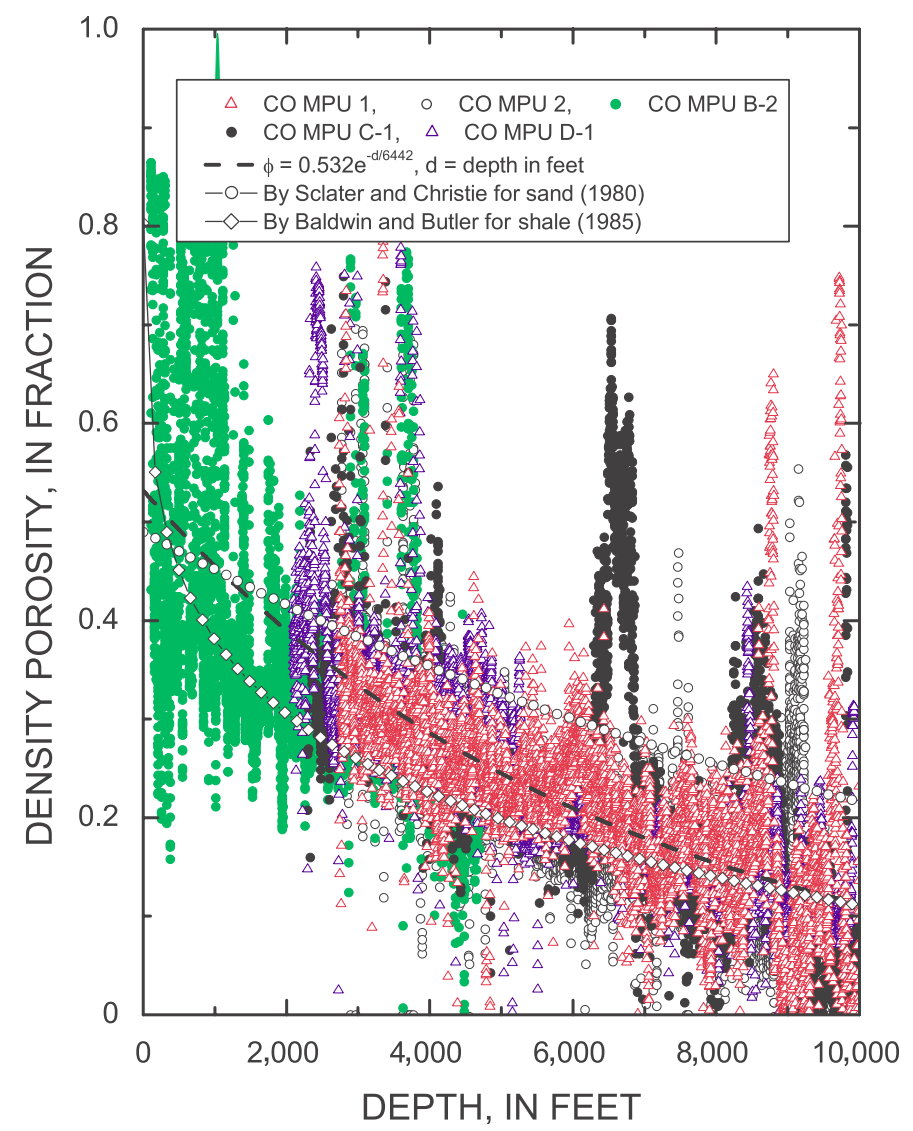

Figure 1. Relation between measured density porosity and depth (compaction) at Milne Point wells with some empirical formulas for shaly sands by Baldwin and Butler (1985) and for clean sandstones by Sclater and Christie (1980). A least-squares fitting to the CO MPU D-1 well is given by $\phi=0.532 e^{-d / 6442}$, where $d$ is the depth in feet and $\phi$ is porosity in fraction.

The horseshoe shape of the velocity and resistivity relationship is persistent in most of the well logs in this area. The circled region in figure 3 indicates possible free gas intervals, where low P-wave velocities are associated with high resistivity, a typical relationship for the free-gas interval. Because of the unsatisfactory quality of P-wave velocity logs, it is not certain whether the low velocities are caused by free gas or by cycle skipping.

\section{Log Analysis}

\section{Gas-Hydrate/Ice Saturations}

The gas-hydrate stability zone (GHSZ) overlaps with the permafrost zone, so it is difficult to differentiate the ice saturation from the gas-hydrate saturation solely on the basis of the available logs such as resistivity and velocity. The physical properties of gas hydrate and ice are similar to each other, so 


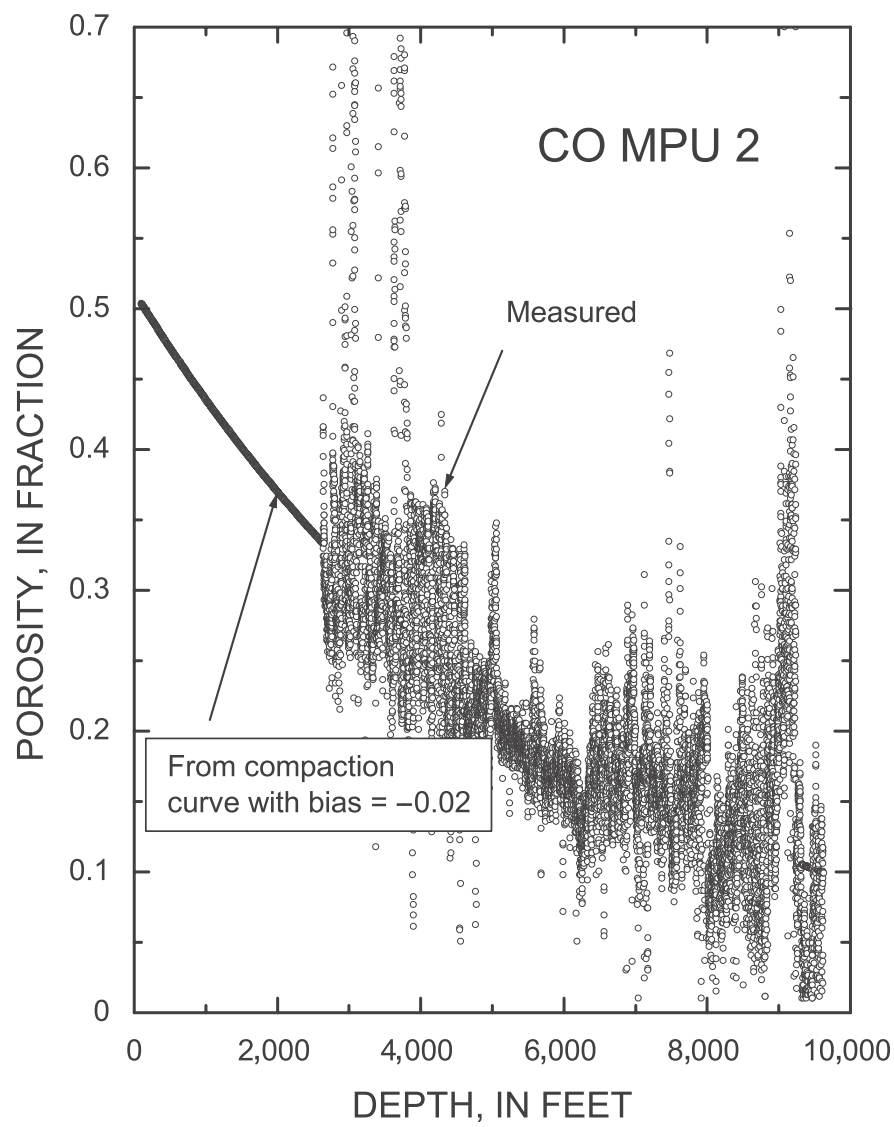

Figure 2. The porosity and depth relationship at the CO MPU 2 well. The compaction curve with a bias of -0.02 is used for the upper part of the well to a depth of 2,635 feet.

their responses to log measurements also are similar. Both gas hydrate and ice are electrical insulators, so there is no electrical resistivity difference between permafrost and gas-hydratebearing sediments. The $\mathrm{P}$-wave velocity of ice (about 3.8 to $4.0 \mathrm{~km} / \mathrm{s}$ ), however, is higher than that of gas hydrate (about $3.2 \mathrm{~km} / \mathrm{s}$ ), so there is a difference in the velocity between permafrost and gas-hydrate-bearing sediments for a given saturation. If a thick gas-hydrate formation exists and both P- and $\mathrm{S}$-wave velocities are measured, the velocity ratio can be used to differentiate ice from gas hydrate. However, S-wave velocities are not available for the GHSZ. Therefore, in this analysis, it is assumed that the pore-filling material in the GHSZ and permafrost interval is gas hydrate. Under this assumption, the saturations estimated from the resistivity are the same as saturations estimated under the assumption of ice. However, the saturations estimated from $\mathrm{P}$-wave velocities using gas hydrate as a pore-filling material should be higher than those estimated under the assumption of ice.

The upper part of P-wave velocity logs appears to be more degraded than resistivity logs by poor borehole conditions. Also there exists uncertainty of ice and gas hydrate as the pore-filling material in GHSZ, so only resistivity logs are used in order to estimate gas-hydrate/ice saturations.

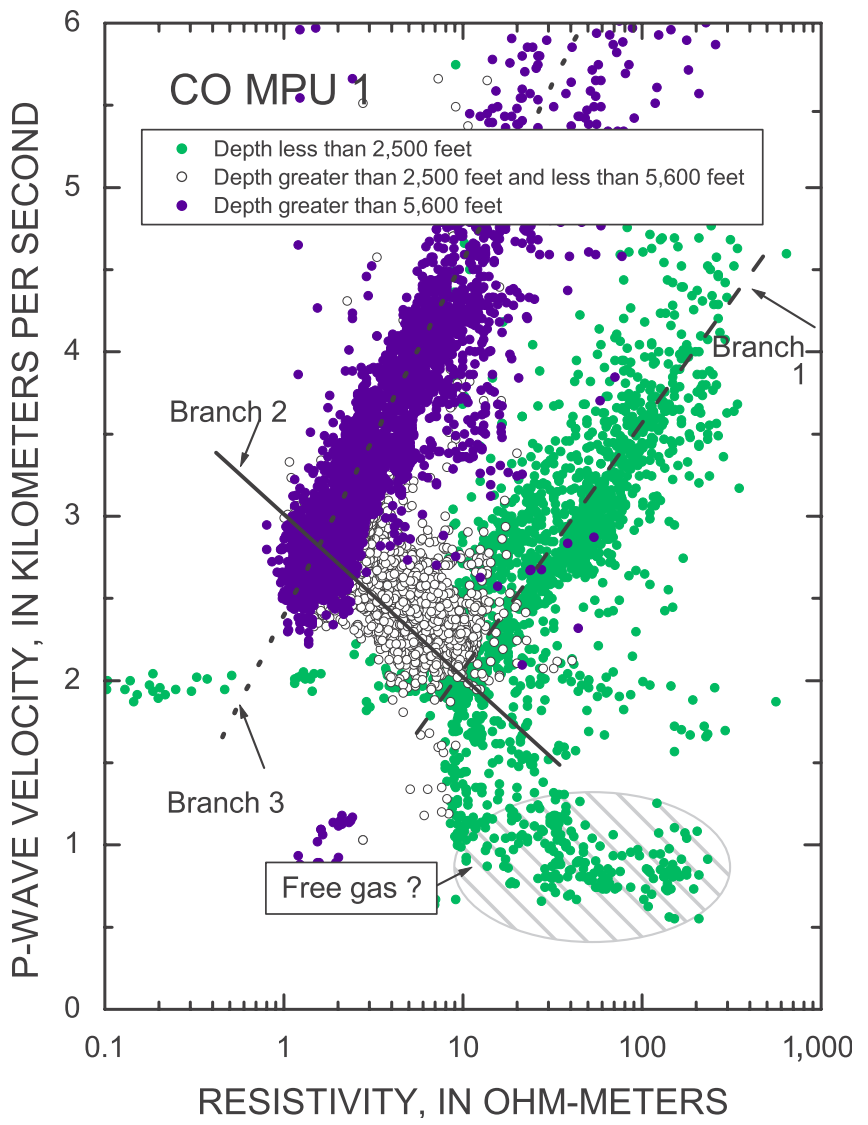

Figure 3. The relationship between P-wave velocity and formation resistivity at the CO MPU 1 well. Three groups depending on depths are shown with approximate linear relationships for each group.

The formation resistivity of sediments $\left(R_{o}\right)$ is given by

$$
R_{o}=\frac{a R_{w}}{\phi^{k} S_{w}^{n}}
$$

where

$a$ and $n$ are constants,

$R_{w}$ is the resistivity of connate water,

$k$ is a cementation factor, and

$S_{w}$ is the water saturation.

From equation 12, the saturation of gas-hydrate/ice $(S)$ can be estimated from the resistivity by using

$$
S=1-\left(\frac{a R_{w}}{\phi^{k} R_{o}}\right)^{1 / 1.9386}
$$

The cementation factor $k$ and apparent resistivity $\left(R_{a}\right)$, $R_{a}=a R_{w}$, in equation 13 can be estimated if resistivity and porosity for water-saturated sediments are available. However, most of the sediments in the upper part of the section inside GHSZ are concentrated either by ice or by gas hydrate, 
so $k$ and $R_{w}$ are not readily evaluated. In this analysis, $k=2.15$ and $a R_{w}=1 \mathrm{ohm}$-meter are used.

The gas-hydrate saturations estimated from the resistivity $\log$ using $R_{a}=1.0 \mathrm{ohm}$-meter and $k=2.15$ at the $\mathrm{CO}$ MPU 2 well are shown in figure 4 . These parameters are not well constrained. However, if the estimated gas-hydrate/ice saturations are high, the estimation errors associated with uncertainties of $k$ and $R_{a}$ are small. For example, the saturation error associated with $k$ with $\Delta \mathrm{k} / \mathrm{k}=0.2$ is less than -5 percent at saturations above 60 percent for 50 -percent porosity sediments. For a given fractional error, the error associated with $R_{a}$ is less than that associated with $k$ (Lee and Collett, 2001) for all porosity and saturation ranges. For a typical reservoir in the Milne 3-D area with $\phi=0.35$ and $S=0.8$, the fractional error of the saturation associated with $\Delta \mathrm{k} / \mathrm{k}=.2$ is about -2 percent.

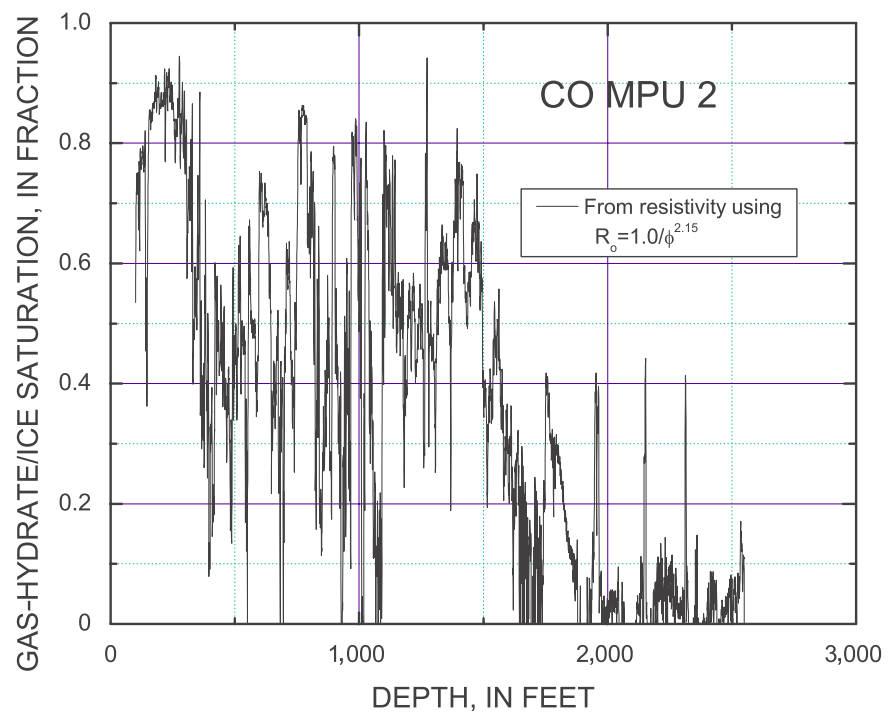

Figure 4. Estimated gas-hydrate/ice saturations from the resistivity $\log$ and density porosity at the CO MPU 2 well. Equation 12 used to estimate saturation with $a R_{W}=1 \mathrm{ohm}$-meter and $k=2.15$. $\phi$, porosity in fraction; $R_{w}$, resistivity of connate water; $R_{0}$, formation resistivity; a and $k$, Archie constants.

\section{Predicting P-Wave Velocity from Resistivity and Porosity Logs}

Usually P-wave velocity log in the upper part of section is either of poor quality or is missing altogether, so it is necessary to predict P-wave velocity for the upper part of the well in order to generate a synthetic seismogram. In general, the P-wave velocities are predicted from the resistivity log by using a least-squares method (Rudman and others, 1975). However, as shown in figure 3, the relationship between velocity and resistivity is complicated in this area. In order to predict velocities, at least three LSF curves are required for CO MPU 1 well, one for each branch. Lee (1999) demonstrated that for gas-hydrate-bearing sediments (likewise for permafrost), velocities predicted from the acoustic equation with gas-hydrate saturations estimated from the resistivity are more accurate than those predicted from the LSF method. The method used in this study is as follows:

1. Estimate gas-hydrate saturations from the resistivity and porosity logs.

2. Using the gas-hydrate saturations, porosity, and clay volume content, calculate the P-wave velocities from the BGTL (Lee, 2002, 2003).

3. If a porosity log is not available for entire interval, use a regional compaction curve with a bias to fit the compaction curve to the trend of measured porosity.

4. If gas content is estimated from the resistivity log, include this in the P-wave velocity prediction as shown in the later section "Effect of Gas on P-Wave Velocity."

Figure 5 shows P-wave velocity calculated from the BGTL with $m=1.45$, the Biot coefficient given in equation 5 , the gas-hydrate saturations shown in figure 4 , the density porosity shown in figure 2 , and clay volume content calculated from the gamma log. In deriving the exponent, $n$, normal hydraulic pressure (no overpressure) is assumed to derive depth-dependent differential pressure. Because most of the pore-filling material is ice in the upper part of the CO MPU 2 well, actual velocities would be a little higher than those shown in figure 5.

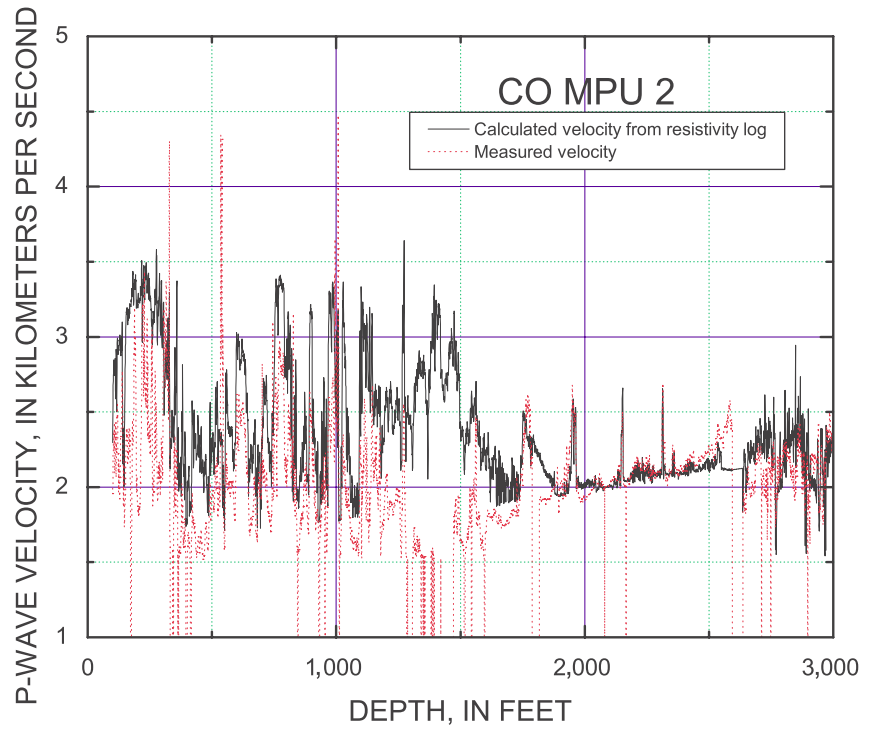

Figure 5. Predicted P-wave velocities using the gas-hydrate/ice saturations (fig. 4) estimated from the resistivity log and porosities are plotted against the measured P-wave velocities at the CO MPU 2 well. BGTL parameter $m=1.45$, depth-dependent differential pressure under normal hydraulic pressure, porosity bias of -0.02 , and $R_{o}=1.0 / \phi^{2.15}$ are used to predict the P-wave velocity.

If porosity derived from the compaction curve is the only variable used in the prediction, porosity monotonically decreases as depth increases to about 2,600 ft. However, as indicated in figure 4 , the gas-hydrate/ice saturation varies with 
depth. Therefore, the P-wave velocities are highly variable due to gas-hydrate/ice saturations and variable clay contents to the depth of 2,600 ft. For depths deeper than 2,600 ft, only porosity and clay volume content are used in predicting the P-wave velocity.

As depth increases, sediments are compacted and consolidated. As a consequence, the nature of sediments changes as depth increases. In order to accommodate the changes of consolidation and compaction with depth, the following geometric mean of the Biot coefficient is proposed, which is appropriate for sediments that are neither consolidated nor unconsolidated.

$$
\beta=\beta_{1}^{\delta} \beta_{2}^{1-\delta}
$$

where

$\beta_{1}$ is the Biot coefficient for unconsolidated sediments (equation 5),

$\beta_{2}$ is the Biot coefficient for consolidated sediments (equation 6), and

$\delta$ is a weight.

When $\delta=1$, the mean Biot coefficient is just the Biot coefficient for unconsolidated sediments. When $\delta=0$, the mean Biot coefficient is that of consolidated sediments.

Sometimes porosity calculated from the resistivity log can be used to predict P-wave velocity. For water-bearing sediments, porosity can be estimated from equation 12 by

$$
\phi_{\text {res }}=\left(\frac{a R_{w}}{R_{o}}\right)^{1 / k}
$$

where

$\phi_{\text {res }}$ is porosity calculated from the resistivity.

Equation 14 assumes that the resistivity of connate water does not change; that is, $R_{a}$ is constant and there is no gas hydrate, gas, or ice in the pore $(S=0)$. Therefore, equation 14 can be used for the deeper part of the section with caution, as shown in Branch 3 in figure 3.

Figure 6 shows the estimated porosity from the resistivity (fig. $6 A$ ) and predicted P-wave velocities using the BGTL (fig. $6 B$ ) with the P-wave velocity at the nearby AR Fiord 5 well. At the AR Fiord 4 well, only gamma and resistivity logs are available. The $\mathrm{P}$-wave velocities were predicted using the BGTL with a variable Biot coefficient and $m$ with $\delta=1$ when depths are less than $1,000 \mathrm{ft}$ and $\delta=0.3$ when depths are greater than $4,000 \mathrm{ft}$. The weight $\delta$ varies linearly with depth between 1,000 and 4,000 ft. At the same time, it is assumed that the constant $m$ varies linearly with $\delta$ in such a way that $m$ $=2$ when $\delta=1$, and $m=4$ when $\delta=0$. The light line represents the predicted P-wave velocity using the porosities from the compaction curve and clay volume content, and the dark solid line represents the P-wave velocity using the porosities derived from the resistivity $\log$ and clay volume content. The general trend of predicted P-wave velocity agrees well with that of the AR Fiord 5 well, and the velocities using the porosity calculated from the resistivity contain much higher frequency. Because there is no P-wave velocity measured at AR Fiord 4 well, the accuracy of predicted P-wave velocity is unknown. It is a worthwhile exercise, however, to predict P-wave velocity from a variety of sources to generate synthetic seismograms for the interpretation of 3-D seismic data in this area.
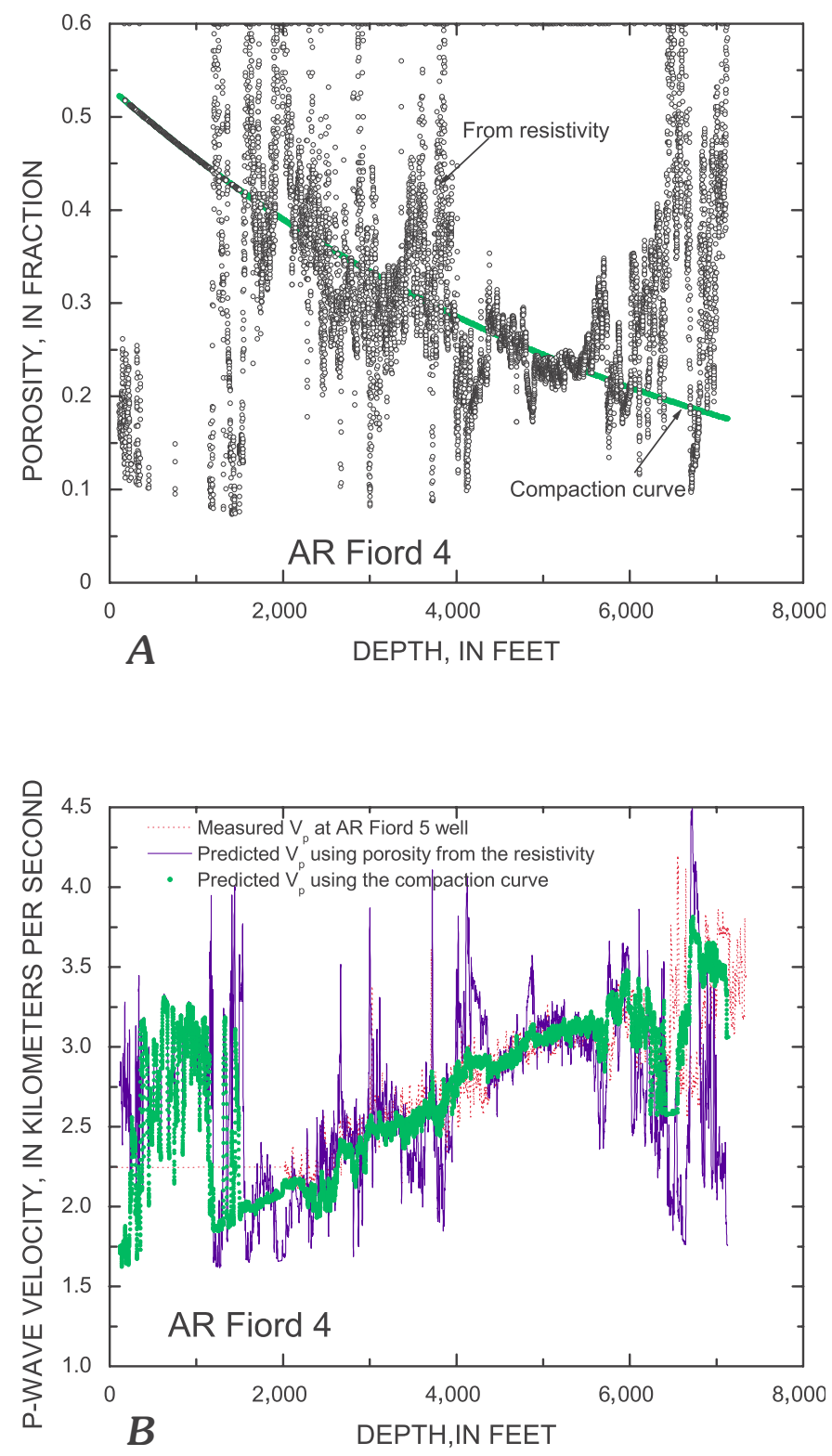

Figure 6. Porosity and velocity at the AR Fiord 4 well. A, Porosities estimated from the resistivity log are compared to porosities from the compaction curve. $B$, Predicted $\mathrm{P}$-wave velocities at the AR Fiord 4 well using the compaction curve and porosity estimated from the resistivity logs are plotted against measured velocities at the nearby well, AR Fiord 5. 


\section{Effect of Gas on P-Wave Velocity}

Usually the density porosity calculated from the bulk density is affected by gas/gas hydrate because a two-component system-matrix and water-is assumed. When a resistivity $\log$ is used to calculate the saturation, the saturation is independent of gas or gas hydrate in the pore space because gas and gas hydrate both are electrical insulators. In the following discussion, it is assumed that the saturations are calculated from the density and resistivity logs. If some of the intervals contain free gas instead of gas hydrate, accurate velocities can be calculated in the following way:

1. Calculate new porosity with the assumption of free gas, instead of gas hydrate, in the pore using the threecomponent system of matrix, water, and gas;

2. Calculate gas content using the new porosity from step 1 ; then

3. Calculate P-wave velocity using the BGT with parameters calculated from the BGTL (Lee, 2004).

Let us define:

$\phi_{a}$ to be density porosity assuming two-component system (matrix and water),

$S_{a}$ to be saturation calculated from the resistivity log using $\phi_{a}$ (equation 13),

$\phi$ to be true porosity accounting for the presence of gas, and $S$ to be true gas saturation.

Then,

$$
\begin{gathered}
\phi_{a}=\frac{\rho_{m a}-\rho_{b}}{\rho_{m a}-\rho_{w}} \\
\phi=\frac{\rho_{m a}-\rho_{b}}{\rho_{m a}-\rho_{g} S-\rho_{w}(1-S)}
\end{gathered}
$$

where

$\rho_{m a}, \rho_{w}, \rho_{g}$, and $\rho_{b}$ are density of matrix, water, gas, and sediments, respectively.

The estimated gas saturations are higher if higher porosities are used. Because the density of gas is less than that of water, $\phi_{a}$ is higher than $\phi$. Therefore, the amount of free gas using true porosity should be less than the one estimated using $\phi_{a}$.

In order to estimate true saturation and porosity from the $S_{a}$ and $\phi_{a}$, the relationship shown in equation 13 can be used. From equation 13,

$$
\phi^{k / 1.9386}(1-S)=\phi_{a}^{k / 1.9386}\left(1-S_{a}\right)
$$

If it is assumed that $k \approx 1.9386$ with $S_{a} \geq 0$, then the following equations can be derived:

$$
\phi=\frac{\left(\rho_{m a}-\rho_{b}\right)+\phi_{a}\left(1-S_{a}\right)\left(\rho_{w}-\rho_{g}\right)}{\rho_{m a}-\rho_{g}}
$$

$$
S=1-\frac{\phi_{a}\left(1-S_{a}\right)}{\phi}
$$

Figure 7 shows an example of calculated P-wave velocities and gas/gas-hydrate saturations for the MO Kuparuk State 7-11-12 well. Figure 7A shows the gas-hydrate saturations $\left(S_{a}\right.$ in equation 20 ) estimated from porosity and resistivity log using $k=2.15$ and $R_{a}=1.0 \mathrm{ohm}$-meter as a solid line (compaction curve with no bias to the depth of 2,500 ft and measured porosity for the rest of the $\log$ ). The gas saturation $\mathrm{S}$ calculated from equation 20 is shown as a dotted line and is a little less than gas-hydrate saturations. Figure $7 B$ shows measured and predicted P-wave velocities. Zone A is probably a gas hydrate interval because the predicted P-wave velocity matches with the measured velocity for gas hydrates. However, zones B and $\mathrm{C}$ may be free gas zones because the predicted velocity using free gas matches a little better with the measured velocity.

\section{Editing P-Wave Velocity}

Predicting P-wave velocity from porosity and clay volume content can be used to edit the velocity log. The proposed scheme is as follows:

1. If the fractional errors of the predicted velocities are greater than a predetermined value, the predicted velocities are used.

2. If the fractional errors of the predicted velocities are less than a predetermined value, the original (measured) velocities are used.

In this text, the fractional error, $E_{p}$, is defined as

$$
E_{p}=\frac{V_{p}^{\text {predicted }}-V_{p}^{\text {measured }}}{V_{p}^{\text {predicted }}}
$$

Figure 8 shows an example of edited P-wave velocities using the predetermined error of zero (fig. $8 A$ ), which is identical to prediction of $\mathrm{P}$-wave velocity, and predetermined error of 0.15 (fig. $8 B$ ). In both cases, the small P-wave velocities in the original logs are replaced with the predicted velocities. As predetermined $E_{p}$ increases, the edited P-wave velocities retain more measured $\mathrm{P}$-wave velocities as shown in figure $8 B$.

\section{Predicting S-Wave Velocity}

In mapping the free gas zone below the GHSZ, the Swave velocities can be very useful and can be used to model the amplitude relative to offset effect. The prediction of S-wave velocity can be accomplished either by the BGTL for gas-hydrate-bearing sediments (Lee, 2003) or by the BGT for partially gas saturated sediments (Lee, 2004). 

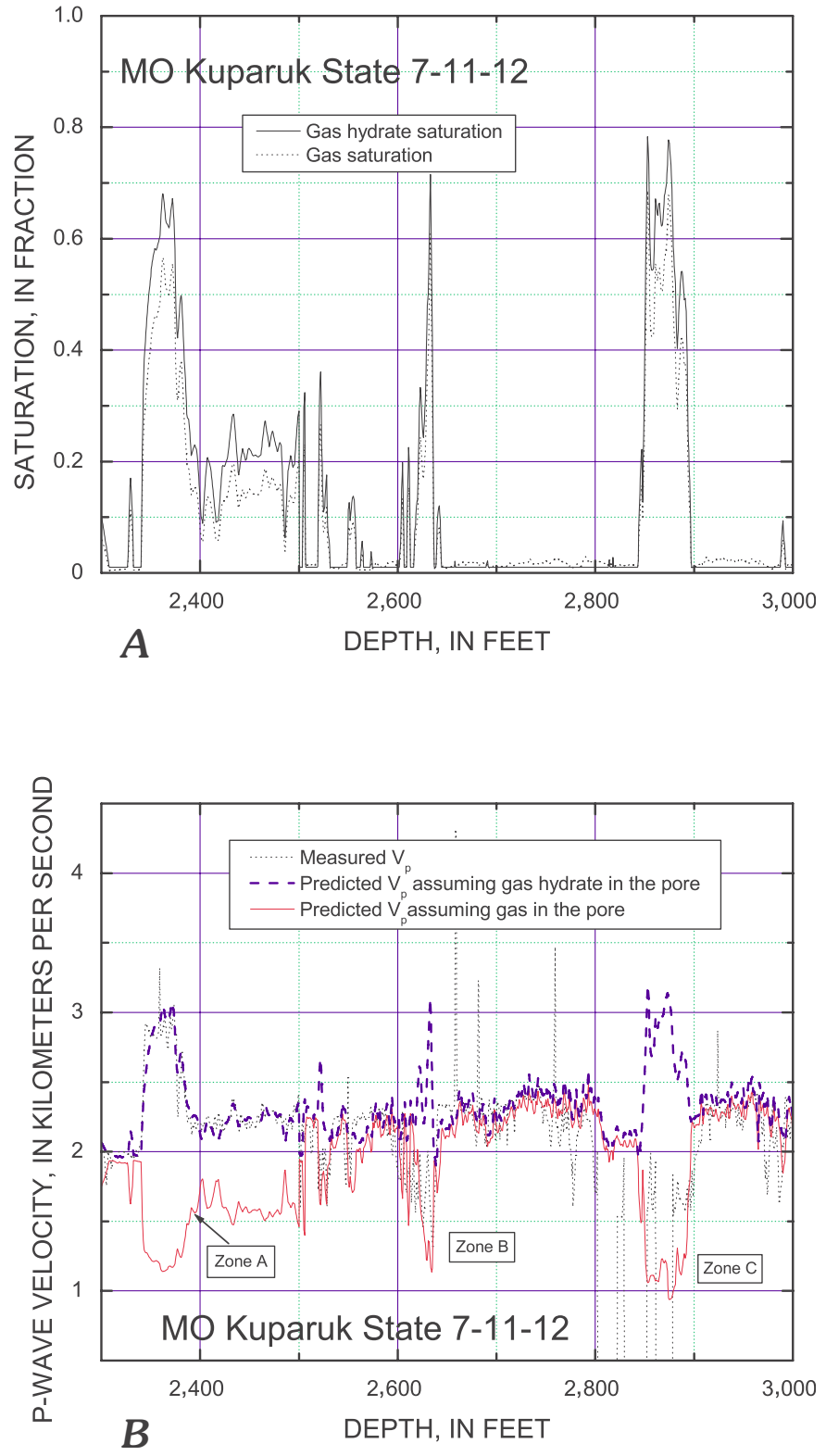

Figure 7. $A$, Gas hydrate and gas saturations estimated from the resistivity log at the Kuparuk State 7-11-12 well. $B$, Predicted P-wave velocities under the assumption of gas hydrate in the pore space (dashed line) and under the assumption of free gas (solid line) with the measured P-wave velocities at the Kuparuk State 7-11-12 well.

Figure 9 shows the result of predicting S-wave velocities along with P-wave velocities for the CO MPU D-1 well. Gashydrate or gas saturations are shown in figure $9 \mathrm{~A}$. The solid lines in figure $9 B$ are the predicted $\mathrm{P}$ - and $\mathrm{S}$-wave velocities, assuming that the pore-filling material is gas hydrate, and the dotted lines are predicted velocities, assuming gas in the pore
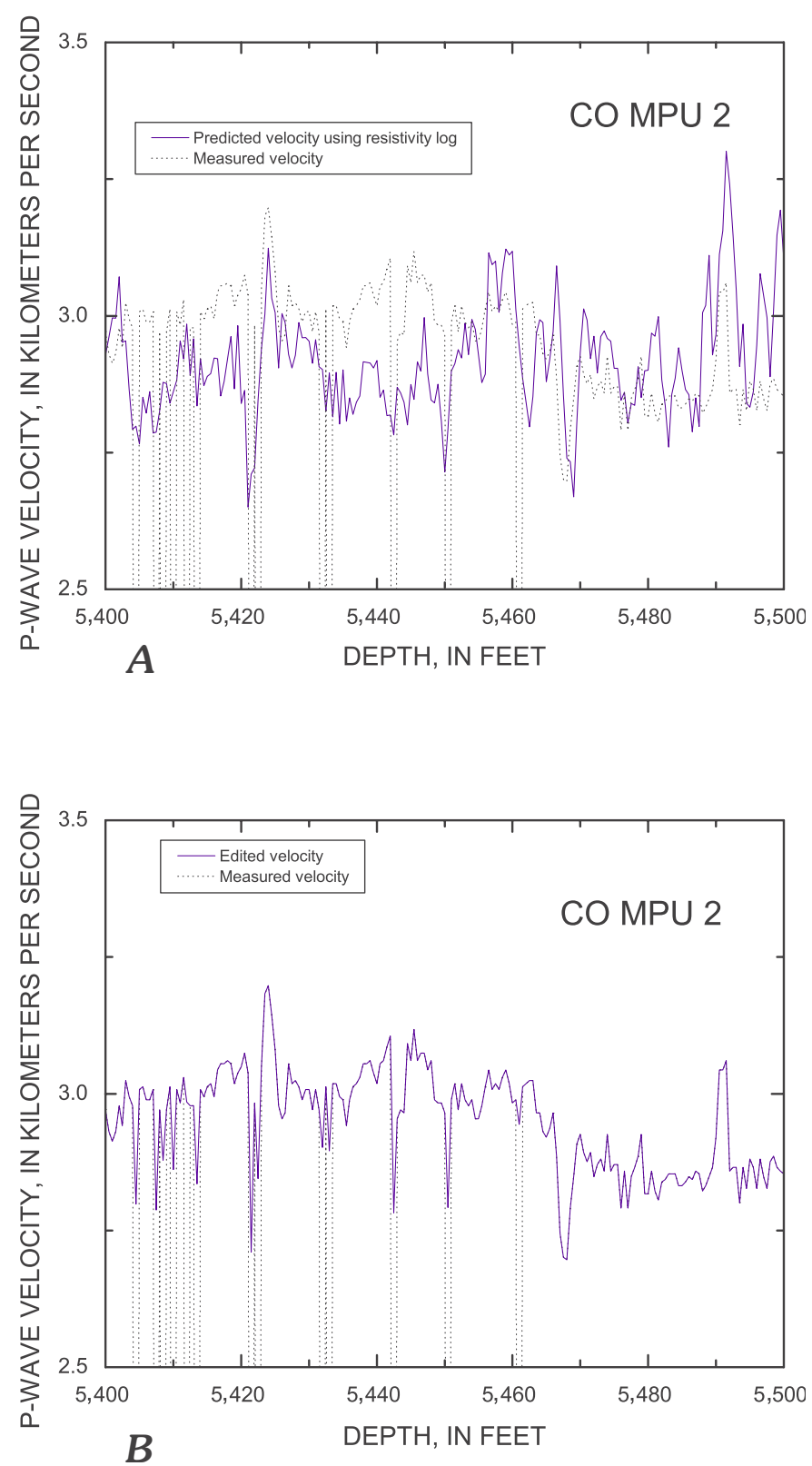

Figure 8. An example of velocity editing using the predicted $\mathrm{P}$-wave velocity at the CO MPU 2 well. BGTL parameter $m=1.45$, depthdependent differential pressure under normal hydraulic pressure, porosity bias of -0.02 , and $R_{o}=1.0 / \phi^{2.15}$ are used to predict the Pwave velocity. $A$, The solid line shows the predicted $\left(E_{p}=0.0\right) \mathrm{P}$-wave velocity. $B$, The solid line shows the edited $\mathrm{P}$-wave velocity using the predicted $\mathrm{P}$-wave velocity as a guide with $E_{p}=0.15$.

space. Velocities are computed under the assumption of patch distribution with a calibration constant $e=6$ (Brie and others, 1995). As shown in figure $9 B$, the effect of gas hydrate on the $\mathrm{S}$-wave velocity is as much as the effect on the P-wave velocity, whereas the effect of free gas on the $S$-wave velocity is much smaller than the effect on the P-wave velocity. 

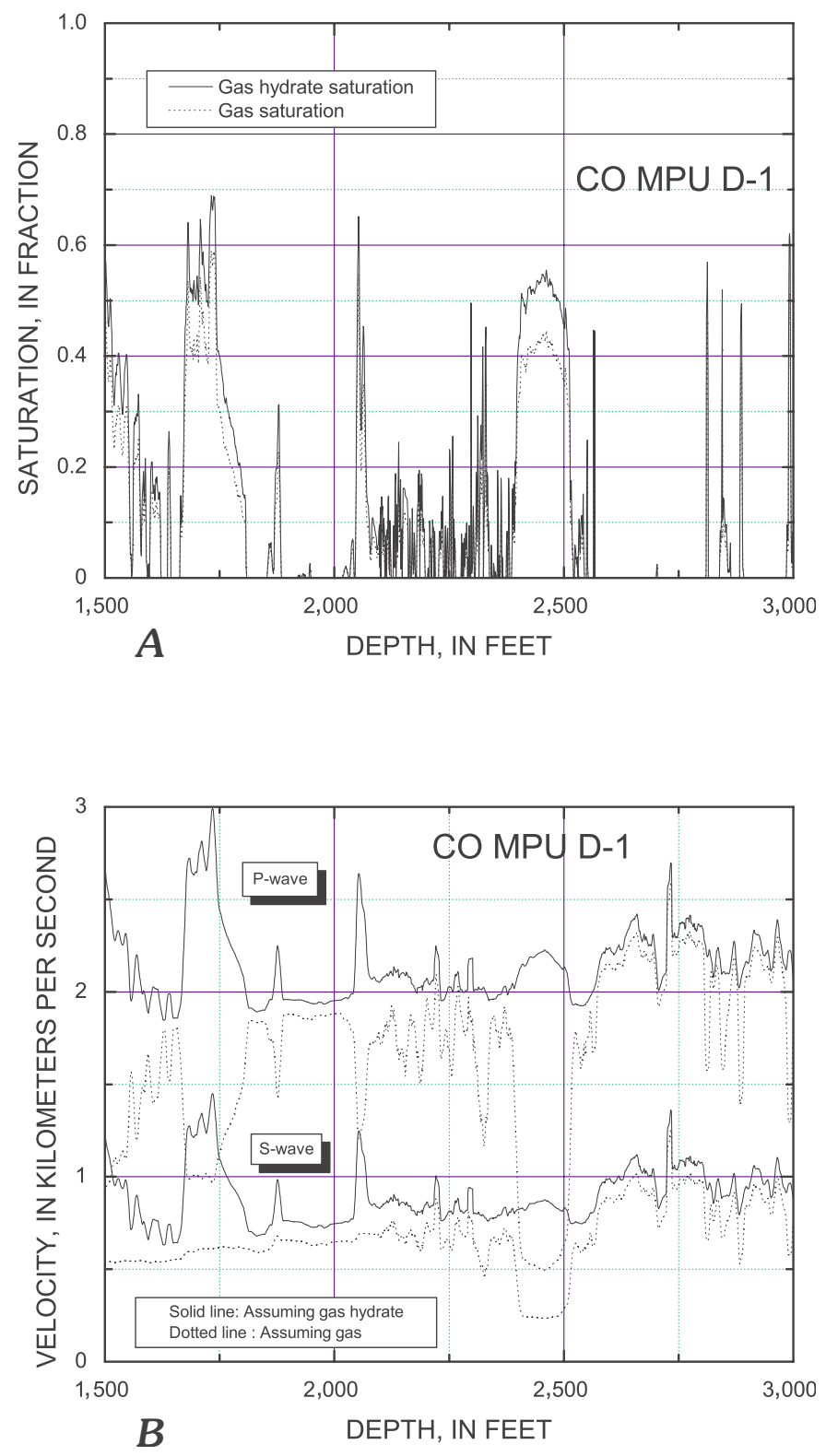

Figure 9. $A$, Gas-hydrate and gas saturations estimated from the resistivity log at the CO MPU D-1 well. $B$, Predicted P- and S-wave velocities under the assumption of gas hydrate in the pore space (solid line) and under the assumption of free gas (dotted line).

\section{Reservoir Properties and Modeling}

\section{Reservoir Properties}

It is demonstrated that gas hydrate accumulates more in clean, porous sediments (Jin and others, 2002). Figure 10 shows the P-wave velocity, density porosity, and clay volume content for sediments within GHSZ at the CO MPU D-1 well. Except for anomalously high porosity spikes, the log responses are of good quality. Figure 10 indicates that cleaner sediments are associated with low P-wave velocity and high density porosity. On the other hand, shaly sands are associated with higher P-wave velocity and lower density porosity. By averaging the $\log$ values with porosities between 0.29 and 0.31 and between 0.39 and 0.41 , typical reservoir properties for gas-hydrate-bearing sediments are derived and shown in figure $11 \mathrm{~A}$. In the modeling, it is assumed that gas hydrate concentrates more in the cleaner sand with the porosity of 0.4 and that the encasing shaly sands with porosity of 0.3 contain no gas hydrate or very low gas-hydrate saturations. Well logs in gas-hydrate-bearing sediments at the Northwest Eileen State 2 well support this model assumption.

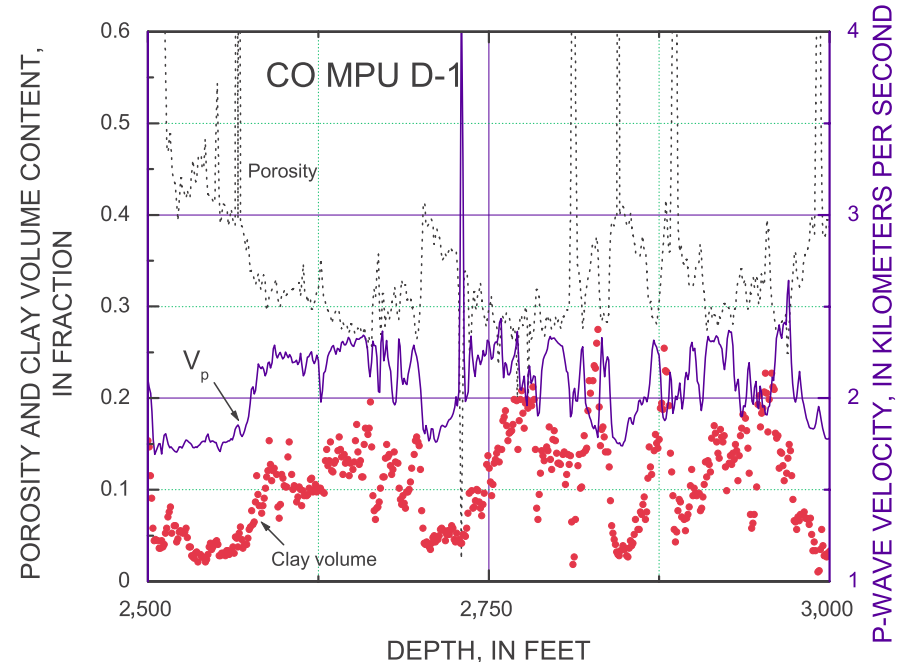

Figure 10. P-wave velocity, density porosity, and clay volume content at the CO MPU D-1 well within gas-hydrate stability zone.

\section{Modeling Velocity}

In order to predict the velocity of gas-hydrate-bearing sediments for a given gas- hydrate saturation, the properties of sediments that do not contain gas hydrate are required, and the pertinent parameters for the BGTL should be derived from the elastic properties of sediments without gas hydrate. Figure $11 B$ shows the measured P-wave velocity, shown in figure 10 , with respect to porosity and shows two modeled P-wave velocities calculated from the BGTL with $m=1$ and $\mathrm{p}=8$ megapascals (MPa). As shown in figure $11 B$, the predicted velocities follow the measured velocities fairly accurately. For example, the large circles in figure 11, which represent measured velocities for the shaly sand and clean sand shown in figure $11 \mathrm{~A}$, do agree with the predicted velocities with greater than 96-percent accuracy. The predicted velocity for the clean sandstone is $1.845 \mathrm{~km} / \mathrm{s}$, whereas the measured velocity is 1.8 $\mathrm{km} / \mathrm{s}$, so there is about 3-percent overestimation. For shaly sand, the predicted P-wave velocity is $2.122 \mathrm{~km} / \mathrm{s}$, whereas the measured velocity is $2.2 \mathrm{~km} / \mathrm{s}$, which is about 4-percent underestimation. 


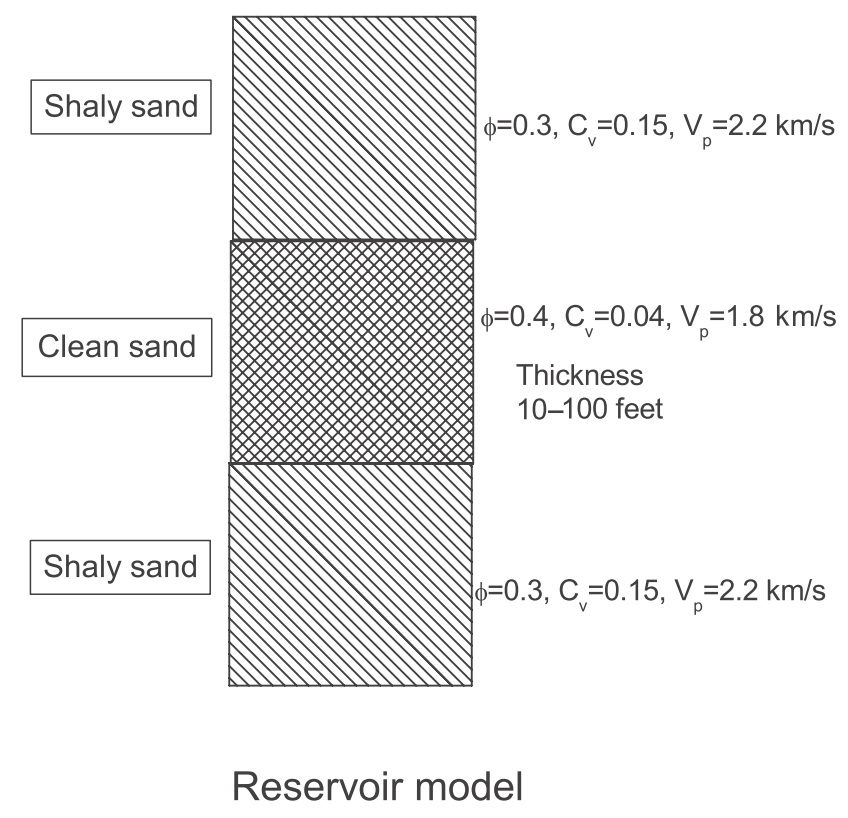

A

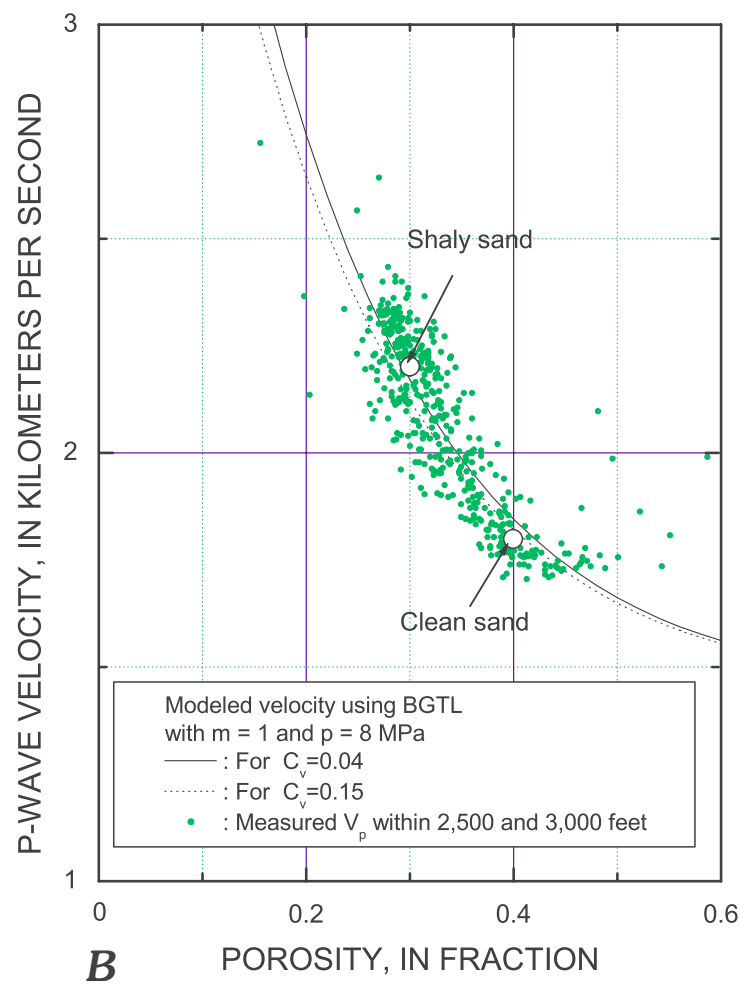

Figure 11. A, Parameters for a typical reservoir of gas-hydrate-bearing sediments. $B$, Graph showing measured P-wave velocities at depths between 2,500 and 3,000 feet at the CO MPU D-1 well and predicted P-wave velocity for the clean sand (reservoir interval) and encasing shaly sandstone. Two large circles represent the average velocity and porosity for clean and shaly sands shown in figure $11 A$. BGTL, modified Biot-Gassmann theory by Lee; $\phi$, porosity in fraction; $C_{v}$, clay volume content in fraction; $V_{p}$, P-wave velocity; $p$, differential pressure; $\mathrm{km} / \mathrm{s}$, kilometers per second; $\mathrm{g} / \mathrm{cm}^{3}$, grams per cubic centimeter; $m$, BGTL parameter; MPa, megapascal.

Figure 12 shows the modeled P-wave velocity, density, and reflection coefficient using the reservoir model shown in figure $11 A$ with respect to gas-hydrate saturation $(S)$ in the clean sand. It is assumed that the shaly sand contains no gas hydrate ( $S=0$ in the shaly sand). The P-wave velocity varies from $1.85 \mathrm{~km} / \mathrm{s}$ at $S=0$ to $3.82 \mathrm{~km} / \mathrm{s}$ at $S=1.0$. Because the density of gas hydrate is less than that of water, the bulk density of gas-hydrate-bearing sediments decreases slightly as the gas-hydrate saturation increases. The reflection coefficient is -0.11 at $S=0$ in the clean sand and is 0.24 at $S=1$ in the clean sand. Note that amplitude is zero near $S=0.4$; that is, total blanking, and the polarity of reflection changes from negative to positive as gas-hydrate saturation increases.

\section{Modeling Amplitude}

Seismic amplitude responses to the reservoir model shown in figure $11 \mathrm{~A}$ depend on the gas-hydrate saturation, thickness of the reservoir, and frequency content of the seismic wavelet. Figure $13 \mathrm{~A}$ shows amplitude responses under the assumption that the encasing shaly sand contains no gas hydrate and gas hydrate is present only in the clean sand, at two dominant frequencies ( 25 and 40 hertz $[\mathrm{Hz}]$ of Ricker wavelet) and two reservoir thicknesses (10 and $30 \mathrm{ft}$ ). Because of the interference, the amplitude variation of the $10-\mathrm{ft}$ reservoir is less than that of the $30-\mathrm{ft}$ reservoir. Figure $13 B$ shows the amplitude response using a 40-Hz Ricker wavelet with two different saturations for the encasing shaly sand. If the shaly sand contains gas hydrate, the amplitude response shifts downward, toward more negative amplitude, compared to the model using no gas hydrate in the shaly sands.

\section{Amplitude Versus Offset (AVO)}

The $V_{p} / V_{s}$ ratios or the Poisson's ratios of water-saturated, gas-hydrate-saturated, and gas-saturated sediments are markedly different, so the amplitude dependence on the offset could provide additional information for the assessment of gas or gas hydrate in this area. Figure 14 shows the modeled P- and $\mathrm{S}$-wave velocities for the clean sandstone reservoir with gashydrate and gas saturations. The density and bulk modulus of free gas were computed from the formula given by Batzle and Wang (1992) assuming that the pore pressure is $8 \mathrm{MPa}$ and the 


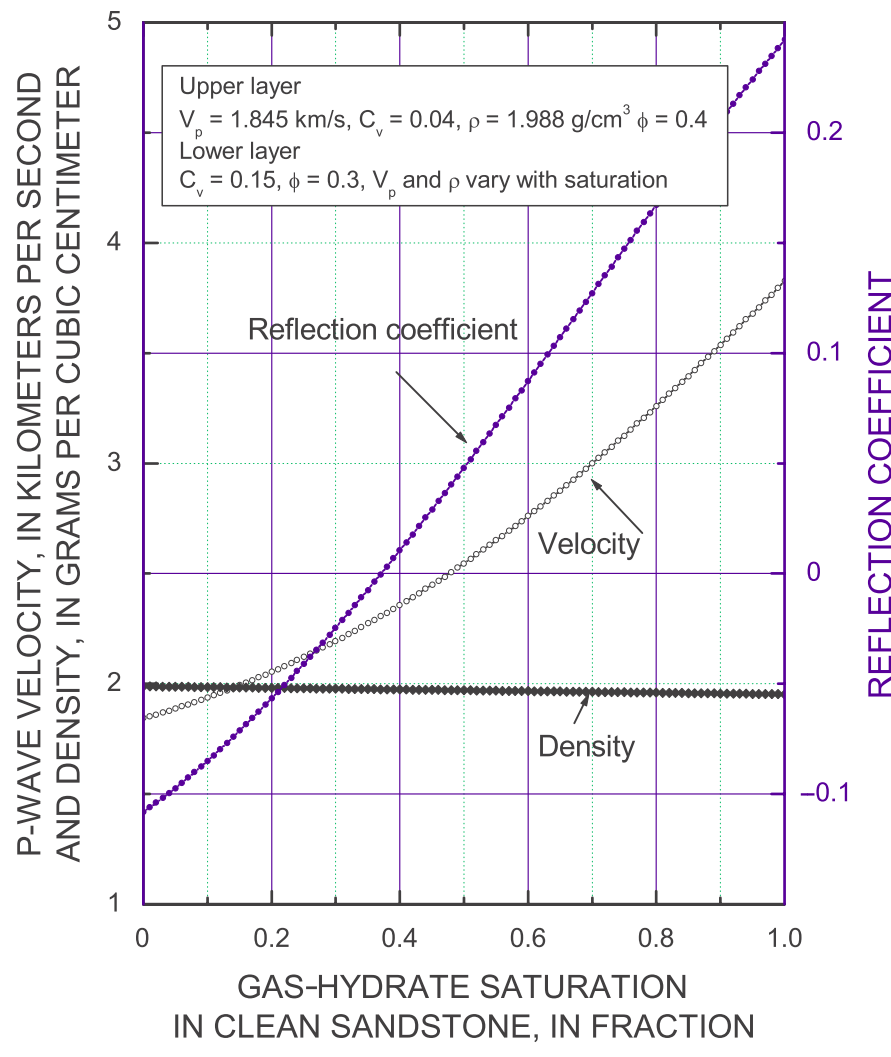

Figure 12. Modeled P-wave velocity, density, and reflection coefficient for the reservoir model shown in figure $11 A$. The gas-hydrate saturation in the encasing shaly sandstone is zero. $\rho$, density; $\phi$, porosity in fraction; $C_{v}$, clay volume content in fraction; $V_{p}$, P-wave velocity; $\mathrm{g} / \mathrm{cm}^{3}$, grams per cubic centimeter; $\mathrm{km} / \mathrm{s}$, kilometers per second.

temperature of reservoir is $5^{\circ} \mathrm{C}$. The velocities of partially gas saturated sediments were computed using the patchy distribution with the calibration constant $e=6$ (Brie and others, 1995). The calculated elastic velocities and densities are shown in table 2 .
Offset dependence of reflection amplitude or amplitude versus offset (AVO) is modeled by assuming that the upper layer is the shaly sandstone, shown in figure $11 A$, without gas or gas hydrate, and the lower sediments contain either gas hydrate or free gas. Figure 15 shows the reflection coefficient relative to the angle of incidence using the parameters shown in table 2. For sediments with gas hydrate (fig. 15A), the magnitude of reflection slightly decreases as the angle of incidence increases until it reaches the critical angle. In this model, there is no critical angle until the gas-hydrate saturation reaches about 25 percent.

Figure $15 B$ shows the reflection amplitude relative to the angle of incidence for partially gas saturated sediments. The magnitude of reflection amplitude increases as the angle of incidence increases beyond about 30 degrees. If the angle of incidence is less than about 30 degrees, the offset dependence of reflection amplitude appears to be similar to each other, even though the magnitude of amplitude is much higher for gas-saturated sediments.

The dotted curve in figure $15 B$ shows the reflection coefficient from an interface whose upper layer is a gas-hydratebearing sediment with $S_{h}=80$ percent and whose lower layer is a partially gas saturated sediment with $S_{g}=80$ percent. This mimics an interface expected at the phase boundary. As indicated in figure $15 \mathrm{~B}$, the amplitude decreases as the angle of incidence increases up to about 60 degrees. If the upper gas-hydrate-bearing sediment has a low saturation such as 20 percent, the amplitude would increase, not decrease, as the angle of incidence increases. It is important to note that if the sediments have high gas-hydrate saturations or high velocities due to cementation of gas hydrate, a negative AVO effect is expected (Ecker and others, 1998; Lee and others, 1996).

The above AVO analysis was accomplished using the exact equation for plane-wave reflection coefficients or Zoeppritz equations (Aki and Richards, 1980). However, in real data analysis, an approximate equation is more appropriate. Aki and Richards (1980) derived the following approximate relationship between angle of incidence and P-P reflection coefficient $\left(R_{p p}\right)$ as

\section{Table 2. Elastic parameters for modeling.}

[ $\phi$, porosity in fraction; $V_{p}$, P-wave velocity; $V_{s}$, S-wave velocity, $\rho$, density; $S_{h}$, gas-hydrate saturation, $S_{g}$, gas saturation; $\%$, percent; km/s, kilometers per second; $\mathrm{g} / \mathrm{cm}^{3}$, gram per cubic centimeter]

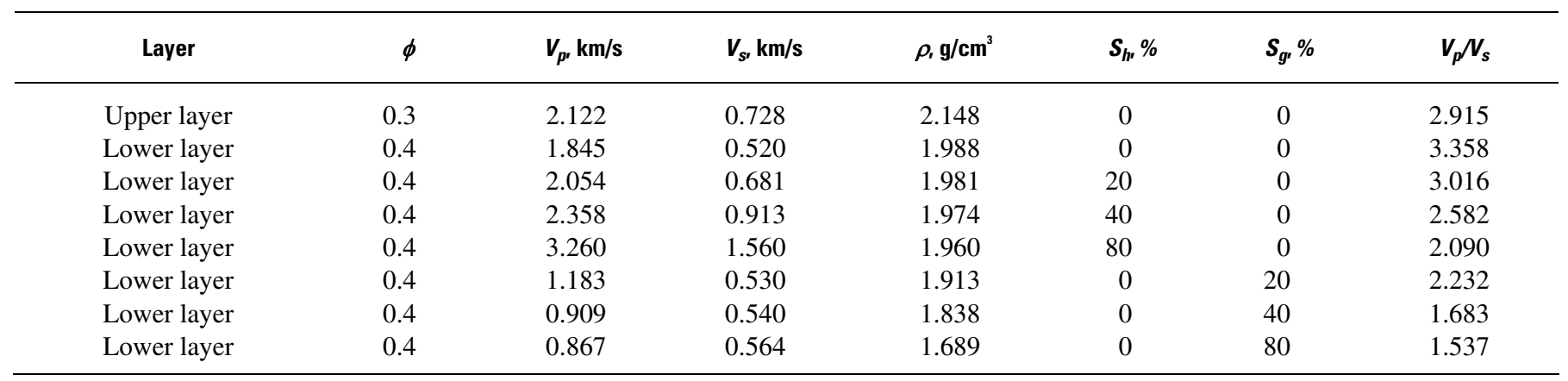




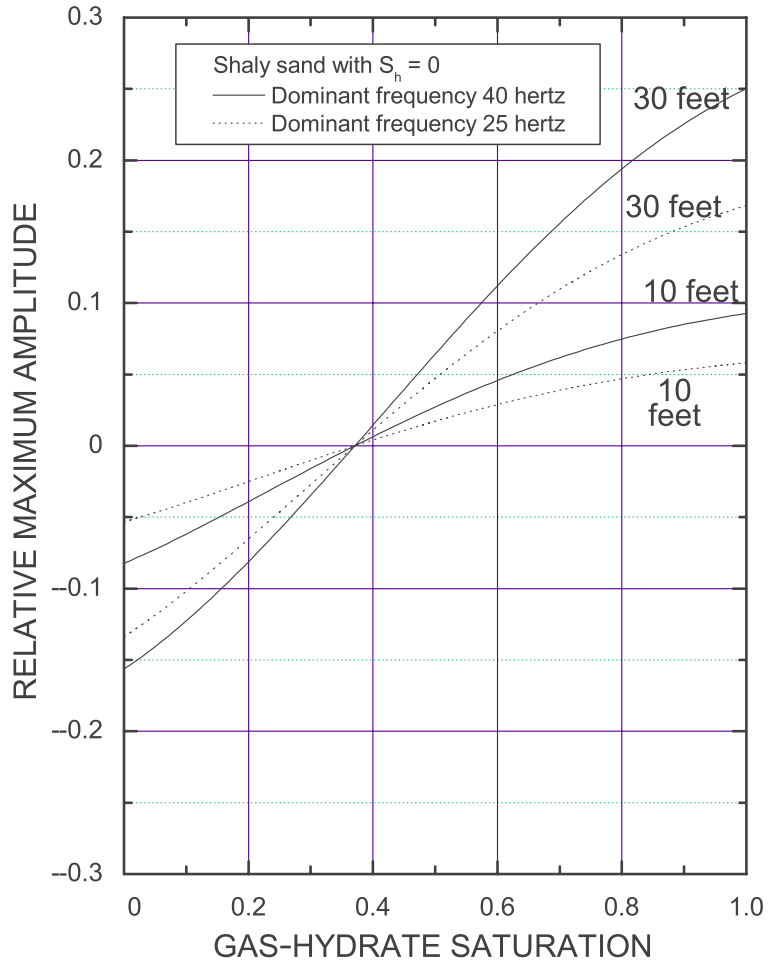

A IN CLEAN SANDSTONE, IN FRACTION

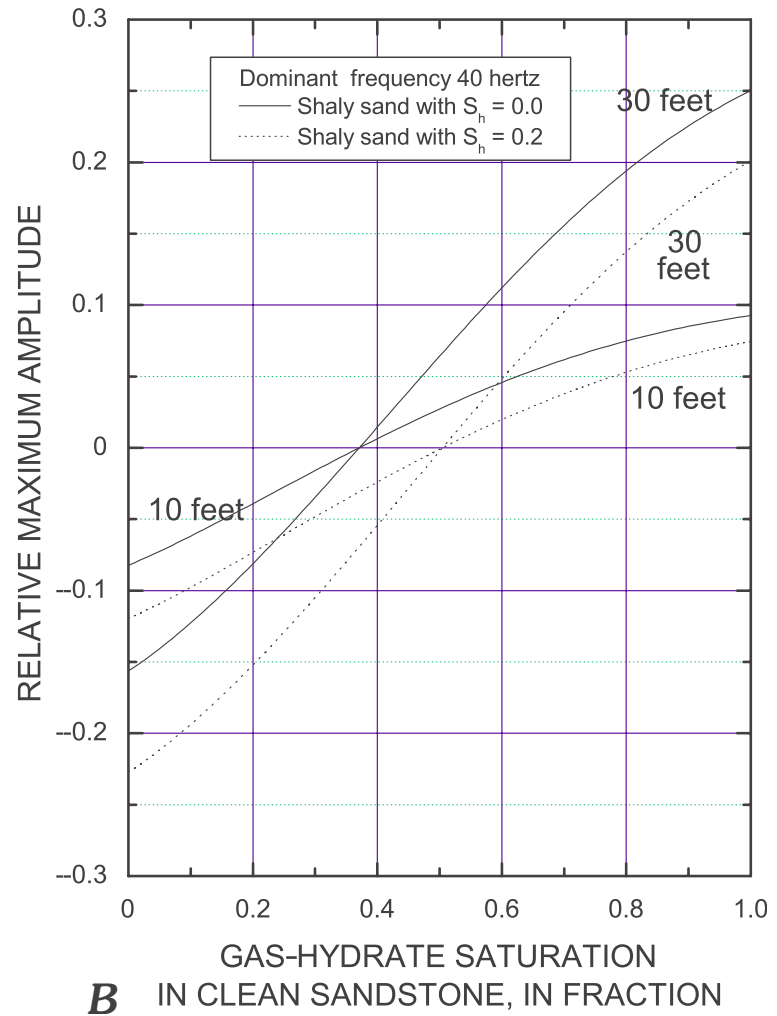

Figure 13. Modeled reflection amplitude. $A$, Comparison of amplitude with respect to the gas-hydrate saturation and to dominant frequency under the assumption of no gas hydrate in the encasing shaly sandstone. $B$, Comparison of amplitude with respect to the gas-hydrate saturation of the encasing shaly sandstone.

$$
R_{p p}(\theta)=A+B \sin ^{2}(\theta)+C \sin ^{2}(\theta) \tan ^{2}(\theta)
$$

where

$$
\begin{aligned}
& A=\frac{1}{2}\left(\frac{\Delta V_{p}}{V_{p}}+\frac{\Delta \rho}{\rho}\right) \\
& B=\frac{1}{2} \frac{\Delta V_{p}}{V_{p}}-2\left(\frac{V_{s}}{V_{p}}\right)^{2}\left(2 \frac{\Delta V_{s}}{V_{s}}+\frac{\Delta \rho}{\rho}\right) \\
& C=\frac{\Delta V_{p}}{2 V_{p}} \text { and }
\end{aligned}
$$

$V_{p}, V_{s}$, and $\rho$ are the average values across the boundary for the P-wave, S-wave and density, respectively.

By least-squares fitting (LSF) of equation 22 to AVO data, coefficients $A, B$, and $C$ can be estimated. Coefficient $A$ is the normal incidence reflection coefficient, and $B$ is often called the AVO gradient, which represents the change of Poisson's ratio across the boundary (Hilterman, 1989).

AVO analysis can be used to identify the pore fluid in sediments. An application of $A$ and $B$ in the analysis of seismic attributes is estimating fluid factor. Smith and Gidlow (1987) introduced fluid factor $(\Delta F)$, which was designed to emphasize deviations from the $\Delta V_{p}=r \Delta V_{s}$ mudrock trend of Castagna and others (1985):

$$
\Delta F=\frac{\Delta V_{p}}{V_{p}}-r\left(\frac{V_{s}}{V_{p}}\right) \frac{\Delta V_{s}}{V_{s}}
$$

For example, if $r=1.16$ and $V_{p} / V_{s}=2$, then

$$
\Delta F=1.251 A+0.58 B
$$

which is zero if the Castagna trend holds.

Figure $16 A$ shows an example of estimated fluid factors using equation 24. AVO modeling was done using the Zoeppritz equations where encasing shales have porosities of 0.2 , 0.25 , and 0.3 with $C_{v}=0.3$ and reservoirs have porosities of $0.3,0.35$, and 0.4 with $C_{v}=0.1$. Gas and gas hydrate with saturations of $0.4,0.6$, and 0.8 were modeled. By LSF to the exact AVO trends with equation 22, $A, B$, and $C$ are estimated and fluid factors are calculated from equation 24 . Figure $16 A$ indicates that even though fluid factors of water-saturated sedi- 


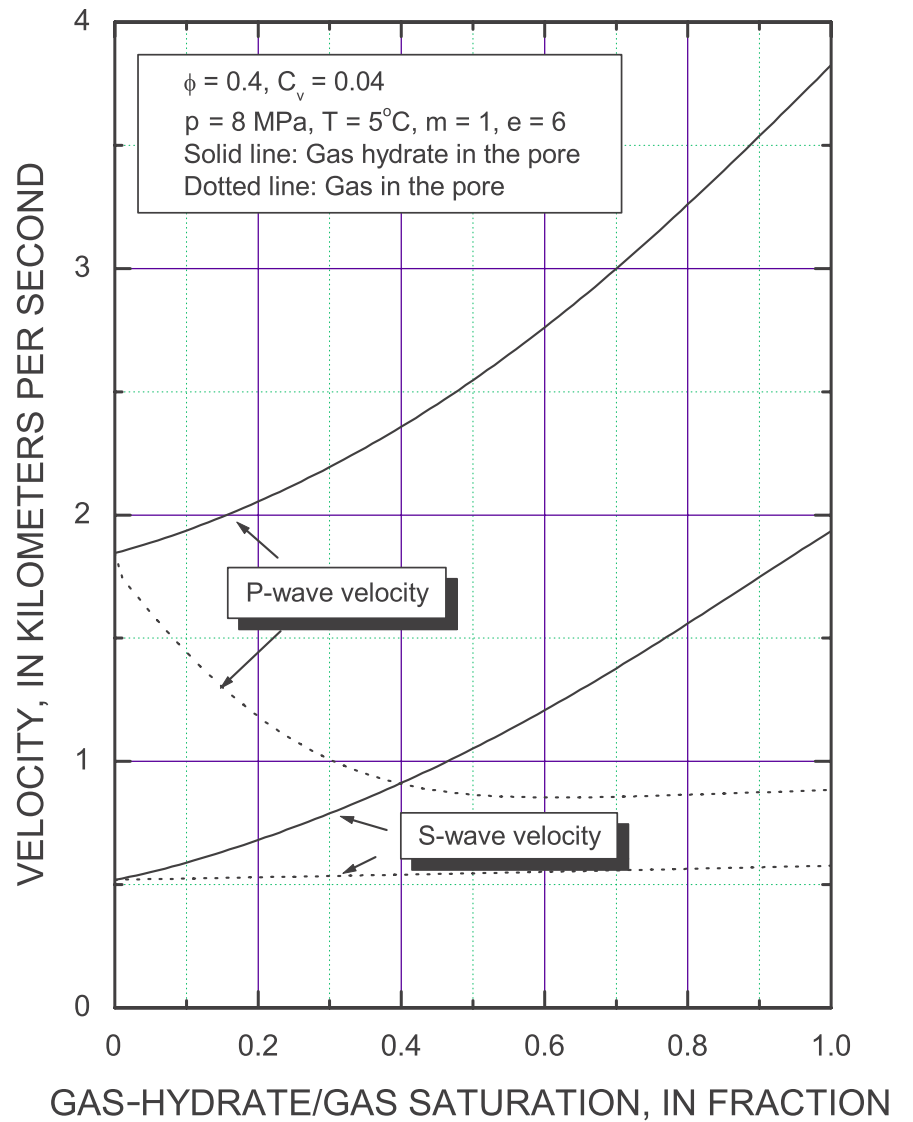

Figure 14. Modeled velocities for gas-hydrate-bearing sediments (solid lines) and partially gas saturated sediments (dotted lines). Density and bulk modulus of gas are calculated from Batzle and Wang (1992) with pore pressure of 8 megapascals (MPa) and the temperature of $5^{\circ} \mathrm{C}$. $\phi$, porosity in fraction; $C_{v}$, clay volume content in fraction; $p$, differential pressure; $T$, temperature; $m$, BTGL (modified BiotGassmann theory by Lee) parameter; $e$, calibration constant.

ments overlap those of gas-hydrate-bearing sediments, fluid factors of partially gas saturated sediments are well separated from those of water- or gas-hydrate-bearing sediments.

\section{Discussion}

\section{Velocity Relative to Gas Hydrate Amount}

The modeled velocity shown in figure 12 can be used to estimate the gas-hydrate saturations from the seismic data if accurate interval velocities can be estimated from the seismic data. One approach is that migrated seismic data are inverted to the interval velocities such as the seislog approach (Lindseth, 1979). Jin and others (2003) applied this method to estimate gas hydrate amount at the South Shetland on the continental margin, Antarctica Peninsula. Also, interval velocities can be estimated using tomography analysis. Tinivella and Lodoro (2000) applied this method to estimate gas-hydrate saturation at the Blake Ridge in the North Atlantic Ocean. Prestack full waveform inversion of large-offset reflection data provides information about $\mathrm{P}$ - and $\mathrm{S}$-wave velocities and bulk density; thus, it is a powerful tool not only to estimate the amount of gas hydrate but also to distinguish gas hydrate from free gas. Dutta and others (2003) demonstrated this approach for a 3-D seismic data interpretation in the Gulf of Mexico. In all of these approaches, the key element is deriving an accurate relationship between the interval velocity and gas-hydrate saturations.

Figure 17 shows various relationships between velocity and gas-hydrate saturations for the Mallik 5L-38 well (dashed lines), from the velocity model shown in figure 12 (circles), and from the predicted velocity at the CO MPU C-1 and CO MPU D-1 wells (dots) with the LSF curve (solid line). The relationship at the Mallik 5L-38 is shifted to the right compared to the modeled relationship (for a given gas-hydrate saturation, the P-wave velocities are higher than the modeled velocity), which is caused by the lower porosity and increased consolidation at the Mallik 5L-38. The average porosity at the Mallik 5L-38 well is 30 percent, whereas the modeled porosity is 40 percent and the average measured porosities (dots) are about 45 percent. The depth to the gas-hydrate-bearing zone at the Mallik 5L-38 is deeper than those analyzed at the CO MPU C-1 and CO MPU D-1wells. The LSF is very close to the modeled velocity relationship. At high saturations, the LSF is shifted toward the left compared to the modeled relationship because most of the high saturations are from the high-porosity permafrost measurements. Therefore, the modeled velocity and saturation relationship shown in figure 12 , which is written as

$$
S=0.87 \ln \left(\frac{V_{p}-0.87}{0.95}\right)
$$

can be used to estimate the amount of gas hydrate from the interval velocities derived from 3-D seismic data.

\section{Seismic Amplitude Relative to Gas Hydrate Amount}

Seismic amplitudes are complexly related to the gashydrate saturations and thickness of reservoir because of constructive and destructive interferences. For a given thickness and frequency, the relationship between gas-hydrate saturation and seismic amplitude is simple. In the case that there is no gas hydrate in the encasing shaly sands, the amplitude relative to saturation for a 30-ft-thick reservoir using a 40-Hz Ricker wavelet (the dominant frequency in the upper section of 3-D volume) can be approximated by

$$
S=\frac{-15.19}{1+e^{(A-1.53) / 0.86}}+13.36
$$




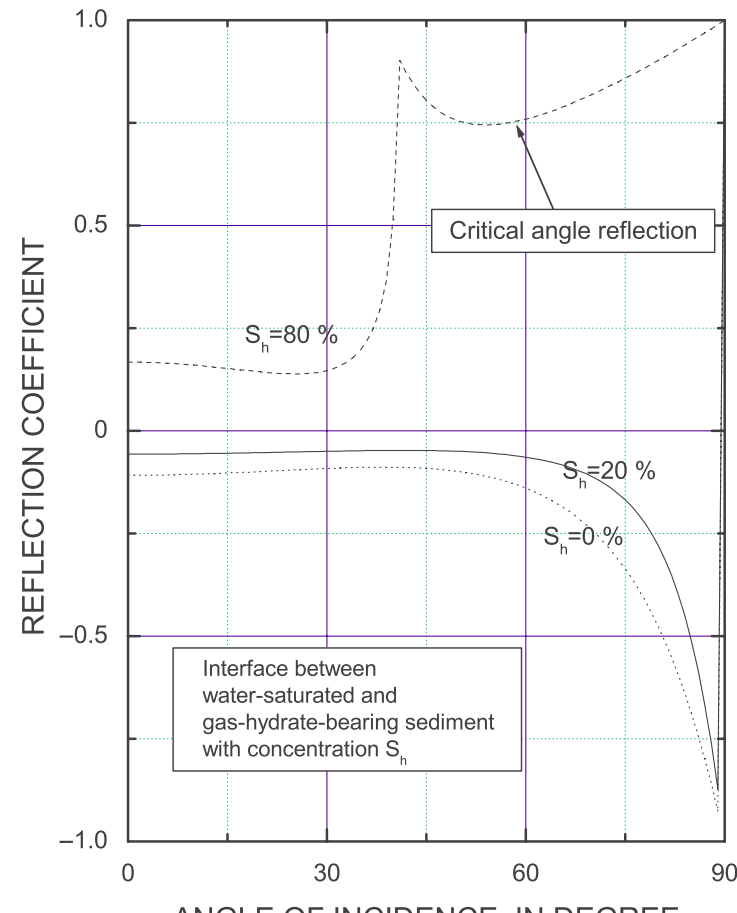

A ANGLE OF INCIDENCE, IN DEGREE

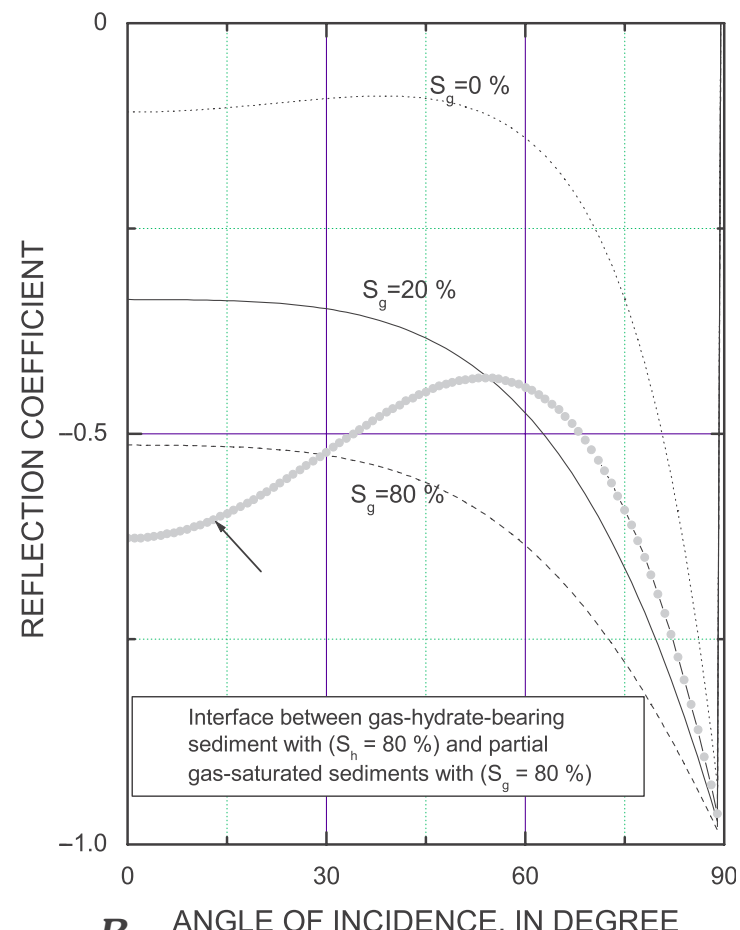

B ANGLE OF INCIDENCE, IN DEGREE

Figure 15. Amplitude versus offset (AVO) relation computed using parameters shown in table 2. A, AVO from the interface between upper water-saturated sediments and lower gas-hydrate-bearing sediments. $B$, AVO from the interface between upper water-saturated sediments and lower partially gas saturated sediments. The circles represent AVO in the case that the upper layer is gas-hydrate-bearing sediment with $S_{h}=80$ percent. $S_{h}$ gas-hydrate saturation; $S_{g}$ gas saturation; \%, percent.
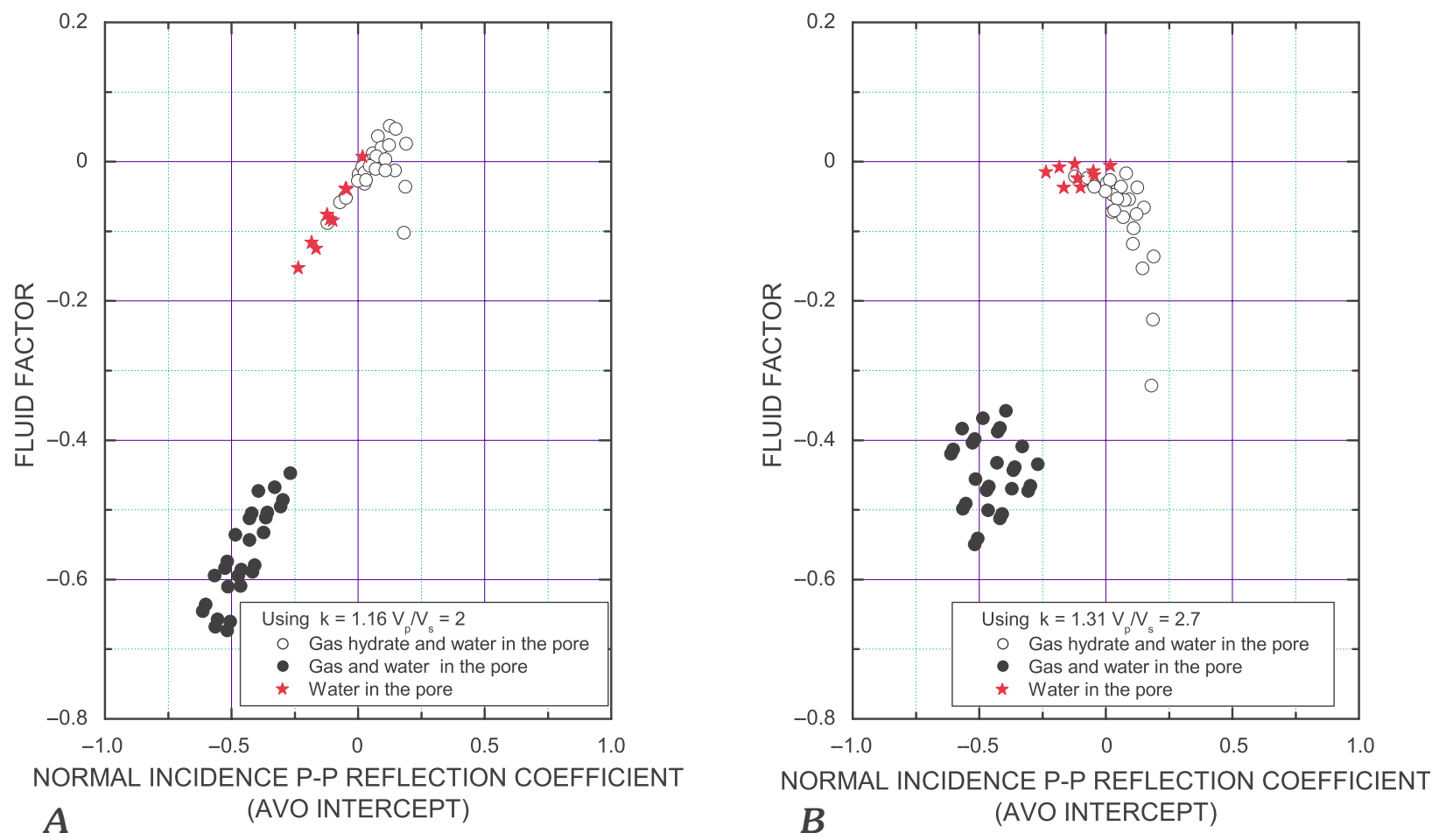

Figure 16. Derived fluid factors from the estimated amplitude versus offset (AVO) intercepts and AVO gradients for modeled AVO data. $A$, Using Castagna mudrock relationship for the velocities of water-saturated sediments. $B$, Using the properties of modeled velocities of unconsolidated sediments expected at this study area. $V_{p}$, P-wave velocity; $V_{s}$ S-wave velocity; $k$, a constant. 


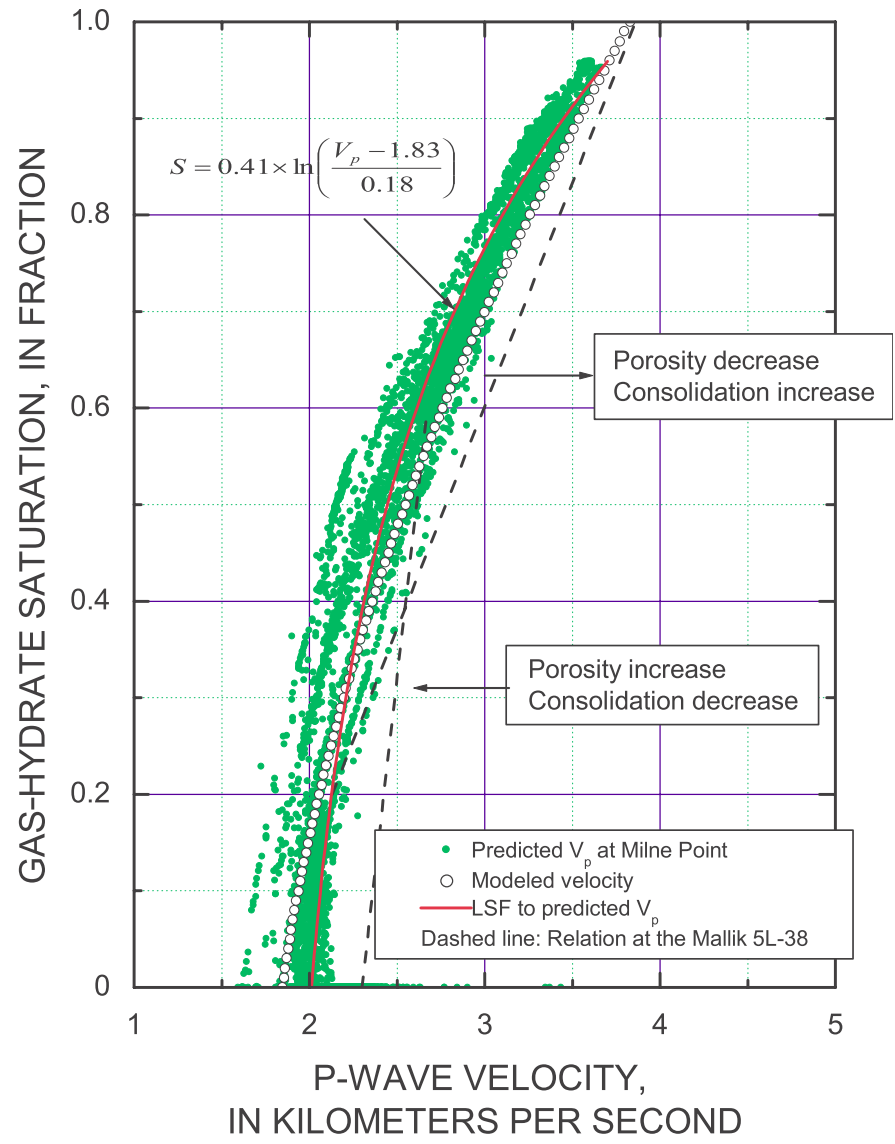

Figure 17. Various relations between gas-hydrate saturation and $\mathrm{P}$-wave velocity. The dashed lines are the relations derived from the well logs at the Mallik $5 \mathrm{~L}-38$, Mackenzie Delta, Canada; circles denote the relations derived from the reservoir model shown in figure $11 A$; dots represent relations derived from the predicted $\mathrm{P}$-wave velocities using the gas-hydrate saturation estimated from the resistivity log at the CO MPU C-1 and CO MPU D-1 wells; the solid line represents a least-squares fit (LSF) to the measured relation. $V_{p}$, P-wave velocity in kilometers per second; $S$, gas-hydrate saturation in fraction.

and for a 10-ft-thick reservoir,

$$
S=\frac{-29.81}{1+e^{(A-0.58) / 0.16}}+29.35
$$

where

$A$ is amplitude of seismic trace including the polarity. As the thickness of reservoir increases beyond about $50 \mathrm{ft}$, the amplitude decreases as gas-hydrate saturation increases. Because the relationship between amplitude and gas-hydrate saturation is complex, it is essential to calculate different reservoir models to extract amplitude information.

\section{Discrimination of Pore Fluid}

Differentiating gas hydrate from free gas in the pore spaces by using seismic data is important in evaluating prospects in this area. As indicated in the AVO analysis, a fluid factor could be used to identify pore fluid by using the unstacked seismic data in the offset domain. The fluids factors shown in figure $16 \mathrm{~A}$ are derived using the Castagna mudrock relationship, which may not be valid for the sediments in the study area. The magnitude of fluid factors of water-saturated sediments increases as the magnitude of intercepts (or $R_{p p}$ ) increases. On the other hand, fluid factors for gas-hydratebearing sediments are scattered around a zero value. This is caused by using the Castagna relationship for water-saturated sediments.

Figure $16 B$ shows fluid factors using the properties of unconsolidated sediments modeled in this investigation. The relationship of modeled $\mathrm{P}$ - and $\mathrm{S}$-wave velocities is given by $V_{p}=1.3137 V_{s}+1.176$. Using this relation and $V_{p} / V_{s}=2.7$, the fluid factor can be found from the following equation:

$$
\Delta F=0.988 A+0.886 B
$$

Figure $16 B$ shows the fluid factors derived using equation 28. The fluid factors of water-saturated sediments scatter around zero value, and the magnitude of fluid factors of gashydrate bearing sediments is a little larger than those of watersaturated sediments. Both figures $16 A$ and $16 B$ suggest that fluid factors, at least in theory, can be used to discriminate gas from gas hydrate in the pore space by using unstacked seismic data in the offset domain.

\section{Conclusions}

The P-wave velocities of gas-hydrate-bearing sediments are predicted using the gas-hydrate saturations estimated from the resistivity log along with porosity and clay volume content using the modified Biot-Gassmann theory by Lee, or BGTL. The effects of free gas in the elastic velocities are modeled using the Biot-Gassmann theory with the Biot coefficient derived from the BGTL.

Predicting P- and S-wave velocities is essential to supplement the missing part of sonic logs in order to tie synthetic seismograms to the 3-D seismic data at the Milne Point area and to model offset-dependent amplitude (AVO). Predicted Pwave velocities can also be used to edit the poor quality sonic logs. Because both gas hydrate and free gas are electrical insulators, the resistivity log cannot distinguish gas hydrate from gas in the pore space. As a consequence, the predicted P-wave velocity contains uncertainty about the pore-filling material near the gas-hydrate phase boundary. The predicted AVO trend based on the model result can be used to differentiate gas hydrate from gas by analyzing the pre-stack 3-D volume. The modeled amplitudes and velocities can be used to relate seismic attributes from the 3-D volume to the gas-hydrate/gas saturations and to spatial distribution of gas or gas hydrate. 


\section{Acknowledgments}

Discussions with T.S. Collett are appreciated very much. I thank P.H. Nelson, J.J. Miller, and T.L. Inks for their comments and suggestions. This work was partly funded by Bureau of Land Management under interagency agreement LAI 020015 and the U.S. Department of Energy under interagency agreement DE-AT26-97 FT 34342.

\section{References}

Aki, Keiiti, and Richards, P.G., 1980, Quantitative seismology theory and methods-Volume 1: New York, W.H. Freeman and Co., $557 \mathrm{p}$.

Baldwin, Brewster, and Butler, C.O., 1985, Compaction curves: American Association of Petroleum Geologists Bulletin, v. 69, p. 622-626.

Batzle, Michael, and Wang, Zhijing, 1992, Seismic properties of pore fluids: Geophysics, v. 57, p. 1396-1408.

Brie, A., Pampuri, F., Marsala, A.F., and Meazza, O., 1995, Shear sonic interpretation in gas-bearing sands: Society of Petroleum Engineers Paper 30595, p. 701-710.

Castagna, J.P., Batzle, M.L., and Eastwood, R.L., 1985, Relationships between compressional-wave and shear-wave velocities in clastic silicate rocks: Geophysics, v. 50, p. 571-581.

Collett, T.S., 1993, Natural gas hydrates of the Prudhoe Bay and Kuparuk River area oil field: American Association of Petroleum Geologists Bulletin, v. 77, p. 793-812.

Collett, T.S., Bird, K.J., Kvenvolden, K.A., and Magoon, L.B., 1988, Geologic interrelation relative to gas hydrates within the North Slope of Alaska: U.S. Geological Survey OpenFile Report 88-389, 150 p.

Dutta, N.C., Snyder, F., Dai, J., and Xu, H., 2003, Impact of Mallik well on the predictive capability of gas hydrates using seismic technology in the Northern Gulf of Mexico: Mallik International Symposium in Makuhari, Program and Abstracts, p. 10-11, December 8-10, 2003, Chiba City, Japan.

Ecker, Christine, Lumlet, D., Dvorkin, J., and Nur, A., 1998, Sediments within gas hydrates: Internal structure from seismic AVO: Geophysics, v. 63, p. 1659-1669.

Hill, R., 1952, The elastic behavior of crystalline aggregate: London, Proceedings of the Physical Society, A65, p. 349-354.
Hilterman, F.J., 1989, Is AVO the seismic signature of lithology?: 59th Annual International Meeting of Society of Exploration Geophysicists, Expanded Abstracts, p. 559.

Inks, Tanya, Collett, T.S., Taylor, D., Agena, W., and Lee, M., 2004, Prospecting for gas hydrate accumulations using 2D and 3D seismic data, Milne Point, North Slope : AAPG Hedberg Conference on Gas Hydrates: Energy Resource Potential and Associated Geologic Hazards, September 12-16, 2004, Vancouver, BC, Canada

Jin, Y.K., Lee, M.W., and Collett, T.S., 2002, Relationship of gas hydrate saturation to porosity and reflection amplitude in a research well, Mackenzie Delta, Canada: Marine and Petroleum Geology, v. 19, no. 4, p. 407-415.

Jin,Y.K., Lee, M.W., Kim, Y., Nam, S.H., and Kim, K.J., 2003, Gas hydrate volume estimations on the South Shetland continental margin, Antarctic peninsula: Antarctic Science, v. 15 , p. $271-282$.

Krief, M., Garta, J., Stellingwerff, J., and Ventre, J., 1990, A petrophysical interpretation using the velocities of $\mathrm{P}$ and $\mathrm{S}$ waves (Full-waveform sonic): The Log Analyst, v. 31, p. 355-369.

Kvenvolden, K.A., 1993, Gas hydrate as a potential energy source-A review of their methane content, in Howell, D.G., ed., The future of energy gases: U.S. Geological Survey Professional Paper 1570, p. 555-561.

Lee, M.W., 1999, Methods of generating synthetic acoustic logs from resistivity log for gas-hydrate-bearing sediments: U.S. Geological Survey Bulletin 2170, 11 p., http: //geology.cr.usgs.gov/pub/bulletins/b2170/, accessed on January 13, 2005.

Lee, M.W., 2002, Biot-Gassmann theory for velocities of gas-hydrate-bearing sediments: Geophysics, v. 67, p. 1711-1719.

Lee, M.W., 2003, Elastic properties of overpressured and unconsolidated sediments: U.S. Geological Survey Bulletin 2214, 10 p., http://geology.cr.usgs.gov/pub/bulletins/b2214/, accessed on January 13, 2005.

Lee, M.W., 2004, Elastic velocities of partially gas-saturated unconsolidated sediments: Marine and Petroleum Geology, v. 21 , no. 6 , p. $641-650$.

Lee, M.W., and Collett, T.S., 1999, Gas hydrate amount estimated from compressional- and shear-wave velocities at the JAPEX/JNOC/GSC Mallik 2L-38 gas hydrate research well, in Dallimore, S.R., and others, eds., Scientific results from JAPEX/JNOC/GSC Mallik 2L-38 gas hydrate research well, Mackenzie Delta, Northwest Territories, Canada: Geological Survey of Canada, Bulletin 544, p. 313-322. 
Lee, M.W., and Collett, T.S., 2001, Gas hydrate estimation error associated with uncertainties of measurement and parameters: U.S. Geological Survey Bulletin 2182, 8 p., http://geology.cr.usgs.gov/pub/bulletins/b2182/ accessed on January 13, 2005.

Lee, M.W., Hutchinson, D.R., Collett, T.S., and Dillon, W.P., 1996, Seismic velocities for hydrate-bearing sediments using weighted equation: Journal of Geophysical Research, v. 101, no. B9, p. 20347-20358.

Lindseth, R.O., 1979, Synthetic sonic logs-A process for stratigraphic interpretation: Geophysics, v. 44, p. 3-26.

Pickett, G.R., 1963, Acoustic character logs and their applications in formation evaluation: Journal of Petroleum Technology, v. 15 , p. 650-667.

Rudman, A.J., Whaley, J.F., Blakely, R.F., and Biggs, M.E., 1975, Transform of resistivity to pseudovelocity logs: American Association of Petroleum Geologists Bulletin, v. 59, p. 1151-1165.
Sclater, J.G., and Christie, P.A.F., 1980, Continental stretching-An example of the post mid Cretaceous subsidence of the central North Sea basin: Journal of Geophysical Research, v. 56, p. 51-58.

Smith, G.C., and Gidlow, P.M., 1987, Weighted stacking for rock property estimation and detection of gas: Geophysical Prospecting, v. 35, p. 993-1014.

Tinivella, Umberta, and Lodoro, E., 2000, The Blake Ridge bottom-simulating reflector transect: Tomographic velocity field and theoretical model to estimate methane hydrate quantities, in Paull, C.K. and others, eds., Proceedings of the Ocean Drilling Program, scientific results, v. 164: College Station, Texas A\&M University, p. 273-281.

Western Atlas International Inc., 1995, Introduction to wireline log analysis: Western Atlas International Inc., chapter 4, $312 \mathrm{p}$.
Published in the Central Region, Denver, Colorado Manuscript approved for publication March 3, 2005 Edited by Mary A. Kidd and Richard W. Scott, Jr. Photocomposition, page layout-Richard W. Scott, Jr. Graphics by the author 